\title{
Simulation of Mesoscale Cellular Convection in Marine Stratocumulus. Part I: Drizzling Conditions
}

\author{
XiaOli ZHOU \\ Department of Atmospheric and Oceanic Sciences, McGill University, Montreal, Quebec, Canada, and \\ Department of Atmospheric Sciences, University of Washington, Seattle, Washington \\ ANDREW S. ACKERMAN AND ANN M. FRIDLIND \\ NASA Goddard Institute for Space Studies, New York, New York \\ PAVLOS KOLLIAS \\ School of Marine and Atmospheric Sciences, Stony Brook University, State University of New York, \\ Stony Brook, and Department of Environmental and Climate Sciences, \\ Brookhaven National Laboratory, Upton, New York
}

(Manuscript received 7 March 2017, in final form 29 September 2017)

\begin{abstract}
This study uses eddy-permitting simulations to investigate the mechanisms that promote mesoscale variability of moisture in drizzling stratocumulus-topped marine boundary layers. Simulations show that precipitation tends to increase horizontal scales. Analysis of terms in the prognostic equation for total water mixing ratio variance indicates that moisture stratification plays a leading role in setting horizontal scales. This result is supported by simulations in which horizontal mean thermodynamic profiles are strongly nudged to their initial well-mixed state, which limits cloud scales. It is found that the spatial variability of subcloud moist cold pools surprisingly tends to respond to, rather than determine, the mesoscale variability, which may distinguish them from dry cold pools associated with deeper convection. Simulations also indicate that moisture stratification increases cloud scales specifically by increasing latent heating within updrafts, which increases updraft buoyancy and favors greater horizontal scales.
\end{abstract}

\section{Introduction}

Large regions of stratocumulus clouds are ubiquitous over cool ocean waters (Wood 2012), and have been consistently observed to organize on horizontal scales of 10-50 km (Agee et al. 1973; Atkinson and Zhang 1996; Comstock et al. 2005; vanZanten et al. 2005; Wood and Hartmann 2006; Sharon et al. 2006), as an example of mesoscale cellular convection (MCC). Because they cover substantial areas of darker, underlying ocean but are not much colder than the surface, they exert little effect on outgoing longwave radiation but strongly reflect incoming shortwave radiation, leading to a net cooling effect on Earth's radiation budget (Hartmann et al. 1992). However, the climate feedback of stratocumulus clouds is uncertain, and their representation in

Corresponding author: Xiaoli Zhou, xiaoliz@uw.edu general circulation models is hampered by incomplete understanding and shortcomings in the parameterization of subgrid-scale motions and organization (e.g., Bony and Dufresne 2005; Bony et al. 2006). This uncertainty motivates our interest to better understand mesoscale organization of stratocumulus.

Stratocumulus commonly exhibit organized structures of closed and open cells, as well as relatively disorganized cellular states (Muhlbauer et al. 2014). Closed cells refer to patterns of primarily cloudy regions surrounded by narrow boundaries of less cloudy air, whereas open cells refer to the inverse: broad areas of less cloudy air surrounded by rings of cloud (Agee et al. 1973). Open-cellular structures are frequently observed embedded in unbroken cloud fields and share similar meteorological conditions of adjacent closed-cellular clouds (Stevens et al. 2003; Wood and Hartmann 2006). Such embedded open-cell features, commonly 
referred to as the pockets of open cells (POCs), are associated with patchy drizzle (Stevens et al. 2005; Rosenfeld et al. 2006; Sharon et al. 2006; Comstock et al. 2005, 2007; Wood et al. 2011). Plentiful aircraft and radar measurements (e.g., Frisch et al. 1995; Miller and Albrecht 1995; Vali et al. 1998; Bretherton et al. 2004; Van Zanten and Stevens 2005; Wood et al. 2011) and numerical studies (e.g., Liou and Ou 1989; Albrecht et al. 1995; Wang et al. 1993; Feingold et al. 1997; Stevens et al. 1998; Savic-Jovcic and Stevens 2008; Wang and Feingold 2009) have suggested that drizzle plays a significant role in determining the climatological cloud cover, thickness, and mesoscale morphology of stratocumulus.

The development of organizational scales is also found in nonprecipitating clouds and even in the cloudless dry convective boundary layer (CBL). By introducing passive scalars in simulations of a dry CBL, Jonker et al. (1999) reported the broadening of the scalar variance spectra in time and its dependence on the ratio of entrainment and surface fluxes. Despite its growth tendency, the aspect ratio in cloudless CBLs is considered to be too small $(<3: 1$; equivalent to horizontal scales of $1-2 \mathrm{~km}$ ) to be classified as mesoscale organization ( $>10: 1$; Schröter et al. $2005)$. It has been suggested that boundary layer organization can reach the scale of MCC only in the presence of moist processes (Schröter et al. 2005). Evidence of mesoscale organization of nondrizzling stratocumulus is provided by observational (Wood and Hartmann 2006) as well as numerical studies (de Roode et al. 2004; SavicJovcic and Stevens 2008), where longwave radiative cooling at cloud top has been found to play an important role in increasing its horizontal scales (Müller and Chlond 1996; Dörnbrack 1997; de Roode et al. 2004). Since we find that nondrizzling cloud organization differs to a large extent from its drizzling counterpart, here we limit our consideration to drizzling stratocumulus. The organization of nondrizzling clouds will be discussed in a companion study.

Drizzle stabilizes the boundary layer by warming the cloud layer and cooling the subcloud layer. In the extreme, it has been suggested that a positive feedback between drizzle and reduction of aerosol numbers can deplete cloud water enough to diminish the cloud-top longwave cooling that drives the vertical mixing that sustains a stratocumulus deck (Ackerman et al. 1993). In a less extreme scenario, the removal of cloud water in updrafts reduces the evaporative cooling of cloudy downdrafts such that downdraft air becomes unsaturated farther above updraft cloud base and no longer negatively buoyant, which is energetically unfavorable to convection (Stevens et al. 1998). Previous studies have also suggested that the dynamic response to subcloud evaporative cooling of drizzle is essential to the formation of open cells and their organization (Savic-Jovcic and Stevens 2008; Wang and Feingold 2009). The divergent flow of subcloud cold pools (which are also moist) results in convergence where they collide with those of neighboring cells, which could promote convection development at cell borders (e.g., Feingold et al. 2010). However, the recent numerical study of Zhou et al. (2017) found that broadening of cloud scales can also occur when scales of variability larger than $200 \mathrm{~m}$ in liquid water potential temperature and total moisture are removed below 300-m altitude. Based on that result, Zhou et al. (2017) suggested that spatial variability of subcloud temperature and moisture is not essential to the MCC of drizzling stratocumulus. A recent study (T. Frederikse et al. 2016, unpublished manuscript) further showed, by uniformly removing water from the cloud layer and redistributing it homogeneously in the subcloud layer, that the spatial distribution of precipitation plays little role in increasing the horizontal scale of stratocumulus clouds. That study hypothesized that the moisture stratification induced by drizzle is essential for increasing the horizontal scales of MCC. The two mechanisms (cold pools and moisture stratification) are by no means mutually exclusive, given the coexistence of horizontal temperature variability and moisture stratification in the presence of drizzle. However, little is currently known about the relative importance of these two mechanisms in promoting cell broadening.

In the present study, the impact of drizzle on mesoscale variability is investigated using eddy-permitting simulations on a large domain. We analyze terms in the prognostic equation of total moisture variance and introduce a nudging approach to investigate the impact of moisture stratification. The remainder of this study is organized as follows. Section 2 documents the model setup and case description. Section 3 shows simulation evolution and the corresponding cloud scales. In section 4 , we present analysis of the total moisture variance budget. The impact of moisture stratification on organizational scales is examined in section 5 . In section 6 , we discuss the mechanism of drizzling stratocumulus organization. We summarize our findings in section 7.

\section{Model and case description}

The Distributed Hydrodynamic Aerosol and Radiative Modeling Application (DHARMA) model (Ackerman et al. 2004, and references therein) is configured for the GEWEX Cloud System Study (GCSS) DYCOMS II second research flight (RF02) model intercomparison case of Ackerman et al. (2009). The initial state is a wellmixed 795-m-deep boundary layer with a 400-m cloud base, capped by a 7-K inversion, with a stratified dry layer 
TABLE 1. Details of simulation setup.

\begin{tabular}{|c|c|c|c|c|c|c|}
\hline Run & $\begin{array}{l}\text { Cloud droplet number } \\
\text { concentration } \\
\left(\mathrm{cm}^{-3}\right)\end{array}$ & $\begin{array}{l}\text { Nudging time } \\
\text { scale below } \\
800 \mathrm{~m} \text { (s) }\end{array}$ & $\begin{array}{l}\text { Nudging scale } \\
\text { factor below } \\
800 \mathrm{~m}\end{array}$ & $\begin{array}{l}\text { Initial } q_{t} \text { gradient } \\
\text { in STBL } \\
\left(\mathrm{kg} \mathrm{kg}^{-1} \mathrm{~km}^{-1}\right)\end{array}$ & $\begin{array}{c}\text { Raindrop } \\
\text { evaporation }\end{array}$ & $\begin{array}{c}\text { Contributions } \\
\text { of moisture to } \\
\text { buoyancy }\end{array}$ \\
\hline $\mathrm{Nd} 10$ & 10 & 7200 & Varying & 0 & $x$ & $x$ \\
\hline $\mathrm{Nd} 35$ & 35 & 7200 & Varying & 0 & $x$ & $x$ \\
\hline Nd65 & 65 & 7200 & Varying & 0 & $\times$ & $x$ \\
\hline Nd10NE & 10 & 7200 & Varying & 0 & Off & $x$ \\
\hline $\mathrm{Nd} 10 \mathrm{H}$ & 10 & 600 & 1 & 0 & $\times$ & $x$ \\
\hline Nd10HS & 10 & 600 & 1 & -1.875 & $\times$ & $\times$ \\
\hline Nd10HS-NoMoist & 10 & 600 & 1 & -1.875 & $\times$ & Off \\
\hline
\end{tabular}

above. DHARMA solves the Ogura-Philips anelastic equations using a forward-in-time projection method and a third-order advection scheme for both velocity and scalars. A dynamic Smagorinsky turbulence model is used to parameterize subgrid fluxes (Kirkpatrick et al. 2006). The cloud microphysics scheme is an adaptation of the two-moment scheme of Morrison et al. (2005) with prognostic saturation excess following Morrison and Grabowski (2008). The assumption of an exponential size distribution for rain has been generalized to a gamma distribution by modifying the process rates that depend on it; here, we assume a shape parameter of 3 for rain. The rain fall speed is parameterized following Seifert (2008). In this study, droplet number concentration is specified. While this simplified treatment cannot address the detailed complexities of cloud-aerosol interactions and drizzle formation, it provides a reasonable starting point for analyzing the impact of drizzle on the surrounding flow and its mesoscale influences (e.g., Berner et al. 2011).

To investigate the impact of drizzle intensity on stratocumulus development, baseline simulations that span a range of prescribed cloud droplet number concentration $N_{d}$ of 10,35 , and $65 \mathrm{~cm}^{-3}$ (Nd10, Nd35, and Nd65; see Table 1) were run for a period of $32 \mathrm{~h}$. Values of $N_{d}$ around $10 \mathrm{~cm}^{-3}$ are not uncommonly observed in open cells over the southeast Pacific (Wood et al. 2011; Terai et al. 2014). To bypass the influence of the largescale meteorological conditions (surface and entrainment fluxes) on the evolution of cloud scales over $32 \mathrm{~h}$, the surface latent and sensible heat fluxes are prescribed, and a nudging approach is used to maintain a steady inversion height, thereby avoiding the slow manifold of boundary layer-depth equilibration described by Bretherton et al. (2010). This approach is generally consistent with evidence from observations that the surface fluxes and boundary layer depths are comparable in POCs and in surrounding closed-cell regions (Wood et al. 2011). Thus, the mean profiles of potential temperature $\theta$ and water vapor mixing ratio $q_{v}$ are nudged toward their initial conditions, preserving local deviations from the mean. By nudging $q_{v}$ instead of total water mixing ratio $q_{t}$, we avoid directly influencing cloud water mixing ratio. In the baseline simulations, the nudging time scale is set to $7200 \mathrm{~s}$ below $800 \mathrm{~m}$ and to $180 \mathrm{~s}$ at $800 \mathrm{~m}$ and above. The scaling factor varies as the square of the sinusoidal function $\left(\sin ^{2}\right)$ from zero (no nudging) at the surface to unity (full-strength nudging) at $800 \mathrm{~m}$ and above (Fig. 1). The full-strength strong nudging above $800 \mathrm{~m}$ effectively fixes the moisture and temperature stratification in the free troposphere and thus maintains the inversion at a near-constant level, while the less-than-unity value below $800 \mathrm{~m}$ permits evolution of boundary layer structure that is similar to that in simulations without nudging (see appendix A). To fully constrain thermodynamic quantities in the boundary layer, a hard nudge of the Nd10 setup below $800 \mathrm{~m}$ is alternatively implemented with the time scale reduced to $600 \mathrm{~s}$ and a scaling factor of unity at all altitudes $(\mathrm{Nd} 10 \mathrm{H}$; Table 1$)$.

The size of the computational domain is $60 \times 60 \times$ $1.5 \mathrm{~km}^{3}$ to accommodate the mesoscale organization that develops. For computational efficiency, the horizontal resolution is set to $\Delta x=\Delta y=300 \mathrm{~m}$ following Wang and Feingold (2009), who found that this somewhat coarse horizontal resolution does not have a significant impact on the cellular structures. At this grid resolution, simulations are sometimes referred to as large-eddy permitting (Green and Zhang 2015) or simply eddy permitting (Nakamura et al. 2012). The vertical mesh is stretched with $\Delta z=5 \mathrm{~m}$ at the surface and within $125 \mathrm{~m}$ of the inversion and dilated following a $\sin ^{2}$ law in the interior of and above the boundary layer. To favor the development of organizational features, an absence of horizontal wind is assumed in the initial profile following Wang and Feingold (2009), who demonstrated that weak wind has little effect on the simulated formation of the cellular structures. To favor monotonic development of organizational features, all simulations represent nocturnal conditions, neglecting interactions 


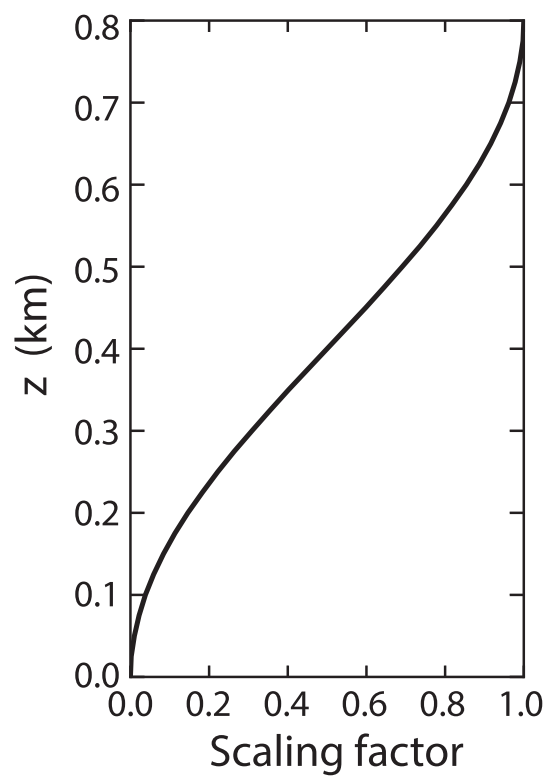

FIG. 1. Scaling factor for soft nudging of the thermodynamic quantities for the baseline simulations.

with solar radiation. To visualize the changes of cloud amount as a result of drizzle, a broadband pseudoalbedo is calculated as $A=\tau /(\tau+13)$, where $\tau$ is optical depth [Bohren (1987), his Eq. (14) with an asymmetry parameter of 0.85 ] assuming cloud droplets and raindrops are geometric scatterers.

\section{Precipitation and stratocumulus organization}

After $\sim 2-3 \mathrm{~h}$ of transient spinup of boundary layer turbulence, the $\mathrm{Nd} 10$ and $\mathrm{Nd} 35$ simulations settle into a quasi-steady state in which properties such as surface and cloud-base precipitation rates, cloud cover, liquid water path (LWP), and stratocumulus-topped boundary layer (STBL) height are nearly constant (Fig. 2). With substantially weaker drizzle, Nd65 reaches its quasisteady-state LWP at $\sim 10 \mathrm{~h}$. Surface precipitation rate varies widely across the simulations (Fig. 2a). It reaches $\sim 1 \mathrm{~mm} \mathrm{day}^{-1}$ for Nd10 and drops to $\sim 0.1 \mathrm{~mm} \mathrm{day}^{-1}$ for Nd35. For Nd65, precipitation is generated in the cloud $\left(\sim 0.1 \mathrm{~mm}\right.$ day $^{-1}$; Fig. $\left.2 \mathrm{~b}\right)$, but negligible amounts reach the surface. The strong drizzle of Nd10 is associated with quasi-steady-state cloud fraction of $\sim 50 \%$ and an opencell structure with highly reflective cell walls at $10 \mathrm{~h}$ (Figs. 2c and 3a), while Nd35 and Nd65 maintain over $90 \%$ cloud cover in the form of closed cells (Figs. $3 \mathrm{~b}$ and $3 \mathrm{c}$ ). Mesoscale structures are found to evolve relatively slowly after $10 \mathrm{~h}$, as shown below (see also additional pseudoalbedo snapshots for Nd10 in Fig. B1). Given that our setup omits a diurnal cycle and $10 \mathrm{~h}$ is a plausible

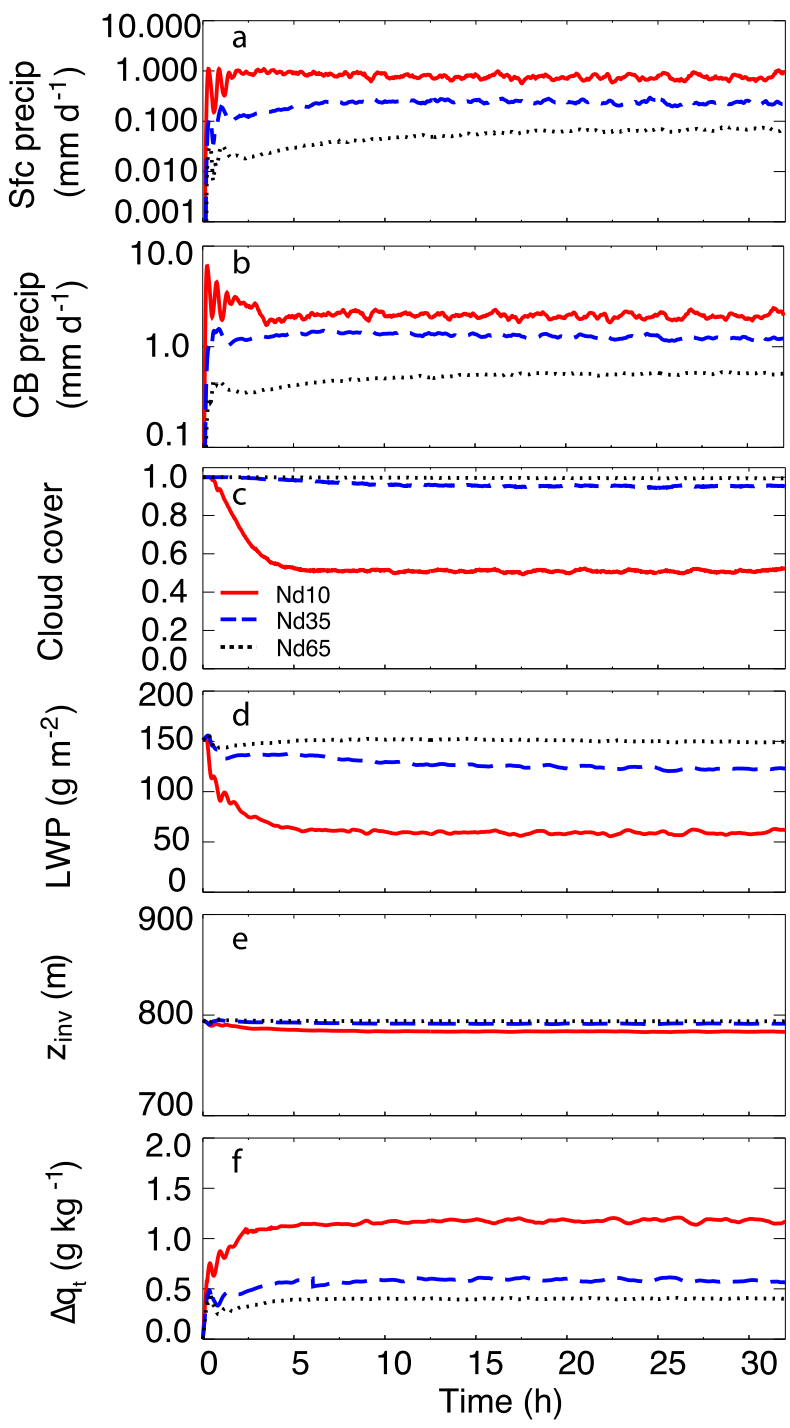

FIG. 2. Evolution of domain averages of (a) surface precipitation rate, (b) precipitation rate at cloud base, (c) cloud cover (fraction of columns with cloud optical thickness $>2$ ), (d) LWP, (e) inversion height (the mean height where $q_{t}=8 \mathrm{~g} \mathrm{~kg}^{-1}$ ), and (f) $\Delta q_{t}$ (difference of mean total water mixing ratio over the bottom and top $25 \%$ of the boundary layer). Setup of simulations as indicated in legend, described in main text, and summarized in Table 1.

nocturnal duration, we largely focus on results at $10 \mathrm{~h}$ hereafter.

Visual inspection of the pseudoalbedo snapshots in Figs. 3a-c suggests that the horizontal scales are larger for open cells relative to closed cells. The organizational scale of the pseudoalbedo can be quantified by applying a two-dimensional (horizontal) spatial Fourier transform followed by an angular integration to obtain the spectral energy per wavenumber $k$ (Fig. 4; de Roode et al. 2004). Figure 4 shows the variance spectra $S$ of pseudoalbedo, optical depth, LWP, and total water 

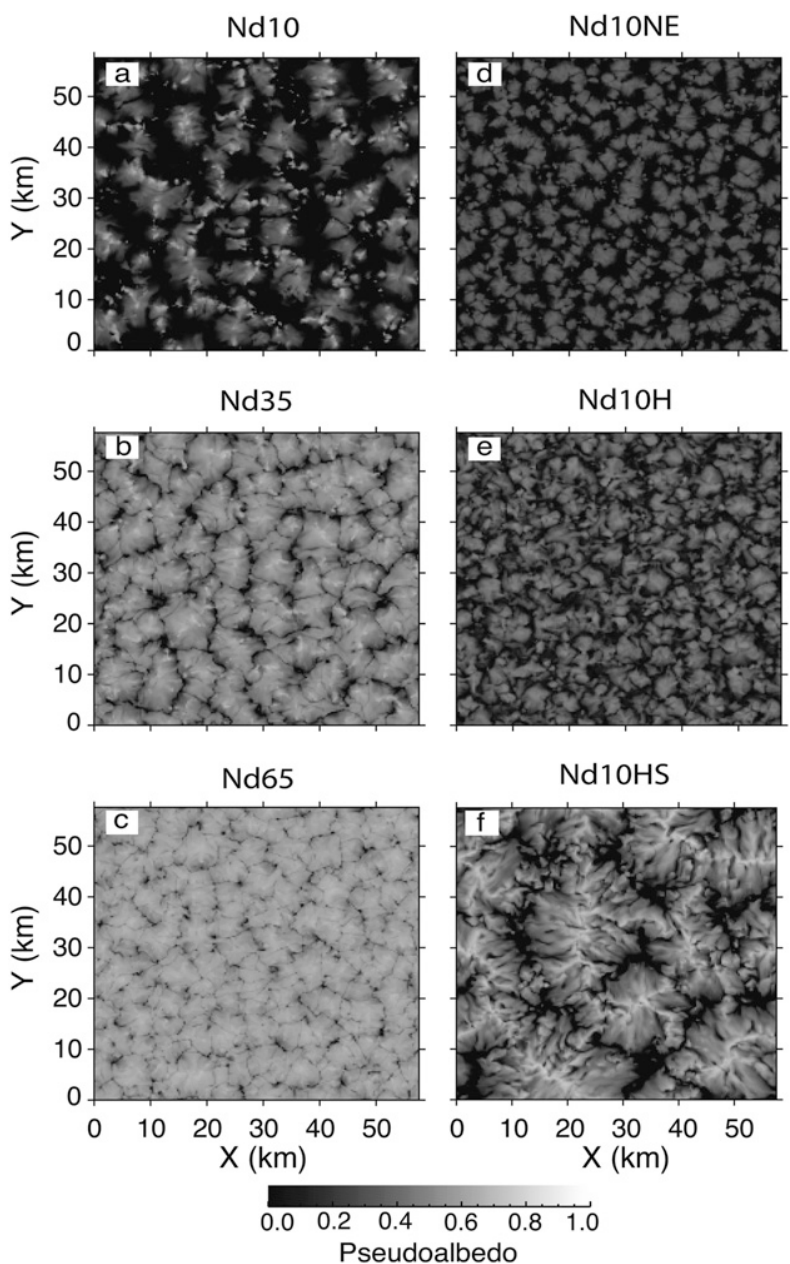

FIG. 3. Snapshots of pseudoalbedo at $10 \mathrm{~h}$ for simulations (a) Nd10, (b) Nd35, (c) Nd65, (d) Nd10NE, (e) Nd10H, and (f) Nd10HS. Setup of simulations described in main text and summarized in Table 1.

mixing ratio $q_{t}$ for $\mathrm{Nd} 10$ at $10 \mathrm{~h}$. The variance spectra are shown in $\log -\log$ space, which requires that $S$ be multiplied by $k$ for the area under the curve to be proportional to the variance (Jonker et al. 1999). Figure 4 reveals that the variance of all four quantities of Nd10 peak at the same (mesoscale) wavelength, which characterizes the typical size of coherent structures occurring in the pseudoalbedo field in Fig. 3a. Since $q_{t}$ is the sum of prognostic variables in the LES, it will be used hereafter as a proxy of the other observables in our investigation of cell broadening.

Consistent with its role as a proxy, in Fig. 5a, it is seen that the variance spectra of $q_{t}$ also peaks at greater power and larger scale for open cells relative to closed cells. Note that while vertical wind variance decreases with increasing drizzle (Fig. 6a) as a result of greater boundary layer stratification induced by evaporative

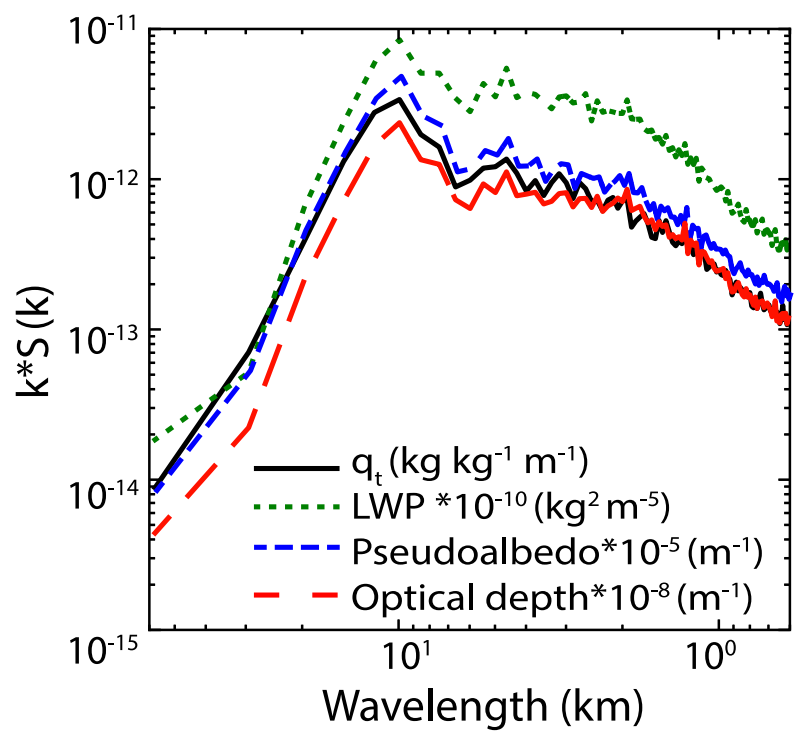

FIG. 4. Variance spectra of total water mixing ratio at $700 \mathrm{~m}$, LWP, pseudoalbedo, and optical depth for simulation Nd10 at $10 \mathrm{~h}$ multiplied by the wavenumber $k$.

cooling, moisture variance tends to increase with drizzle (Fig. 5a). A corresponding spectral length scale $\Lambda_{r}=1 / k_{r}$ is calculated from each spectrum in time (Fig. 5b), in which $k_{r}$ is the critical wavenumber where two-thirds of the variance resides at wavenumbers larger than $k_{r}$. The spectral length scale $\Lambda_{r}$ is analogous to the spectral peak but is less sensitive to noise (de Roode et al. 2004) and is used here to characterize cloud organizational scale, based on total moisture. Further explanation for our preference for this metric over the spectral peak is provided in appendix B.

In contrast to the relatively faster adjustment of domain-mean quantities (e.g., LWP adjustment over $\sim 3 \mathrm{~h}$ in Nd10 and Nd35 in Fig. 2d), cloud scales consistently take $\sim 10-12 \mathrm{~h}$ to reach a quasi-steady state (Fig. 5b). Furthermore, although smaller $N_{d}$ is associated with less overcast conditions and thus less cloud-top cooling, the moisture variance and its length scale are noticeably amplified when $N_{d}$ is decreased (Fig. 5). This amplification signifies a role for drizzle in broadening cloud scales, which differs from nondrizzling stratocumulus, where cloud-top radiative cooling is found to be essential for setting horizontal scales (Müller and Chlond 1996; Dörnbrack 1997; de Roode et al. 2004).

Figure 6 shows that heavier drizzle is associated with increased atmospheric stability, weaker convection (reduced values of $\overline{w^{\prime} w^{\prime}}$ ), and a more bimodal vertical structure of turbulence, in accordance with previous studies (Stevens et al. 1998; Savic-Jovcic and Stevens 2008). Weaker convection is unable to maintain a well-mixed 

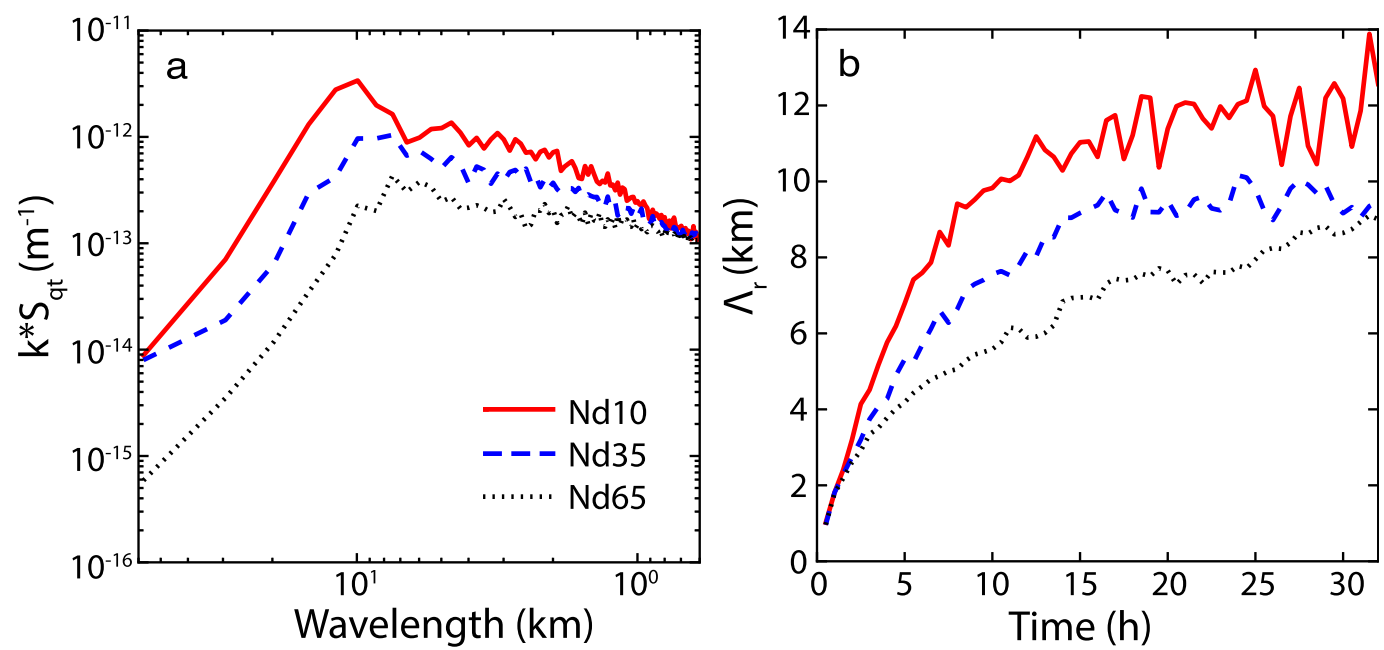

FIG. 5. (a) Variance spectra of total water mixing ratio at $700 \mathrm{~m}$ at $10 \mathrm{~h}$ multiplied by the wavenumber $k$ and (b) temporal evolution of total water mixing ratio variance length scale (defined in text) at $700 \mathrm{~m}$ for $\mathrm{Nd} 10, \mathrm{Nd} 35$, and Nd65. Simulations as in Fig. 2.

STBL, as evident in the stratification of liquid water potential temperature $\theta_{l}$ and total water mixing ratio $q_{t}$ (Figs. 6b and 6c). The near-surface $\theta_{l}$ and $q_{t}$ for $\mathrm{Nd} 10$ (with open cells) are $\sim 0.7 \mathrm{~K}$ cooler and $1 \mathrm{~g} \mathrm{~kg}^{-1}$ moister than for Nd65 (with closed cells). Such temperature and moisture stratifications are consistent with measurements in POCs reported by Wood et al. (2011). Differences in moisture stratification between cases can be also seen in Fig. 2f, which shows the domainaverage $\Delta q_{t}$, computed as the difference between the mean $q_{t}$ over the bottom $25 \%$ and over the top $25 \%$ of the STBL (per Jones et al. 2011). We note that the weaker convection depends to a large extent on the temperature stratification, which is a prerequisite for the moisture stratification. As will be demonstrated below, the moisture stratification in the boundary layer plays a key role in developing the organization of drizzling stratocumulus in simulations.

\section{Prognostic equation of the resolved total moisture variance}

The mesoscale variability is predominantly related to the horizontal distribution of moisture. Although moisture variance varies with height, the horizontal scales of moisture variance are strikingly similar throughout the depth of the boundary layer (beyond the immediate neighborhoods of the surface and capping inversion), as seen in the similarity of the spectral shapes at different heights in Fig. 7a. Also, the magnitude of moisture variance at a given level generally correlates with its scale (cf. Figs. 7b and 7c with Fig. 5b), consistent with Kolmogorov's theorem that the spectral density of an energy spectrum can be predicted by a cascade of energy to small scales from the large scales at which it is generated. This reasoning motivates a detailed inspection of the moisture variance. Inspired by de Roode et al. (2004), we consider the prognostic Reynolds-averaged variance equation for total water mixing ratio (Stull 1988):

$$
\begin{aligned}
& S_{q_{t}} \equiv \frac{\partial \overline{q_{t}^{\prime 2}}}{\partial t}=-2 \overline{w^{\prime} q_{t}^{\prime}} \frac{\partial \overline{q_{t}}}{\partial z}-\frac{1}{\bar{\rho}} \frac{\partial \overline{\bar{\rho} w^{\prime} q_{t}^{\prime 2}}}{\partial z}+2 \frac{\overline{q_{t}^{\prime}} \frac{\partial\left(\bar{\rho} V_{c} q_{c}\right)^{\prime}}{\partial z}}{\partial z} \\
& +2 \overline{\frac{q_{t}^{\prime}}{\bar{\rho}} \frac{\partial\left(\bar{\rho} V_{r} q_{r}\right)^{\prime}}{\partial z}}-\bar{\varepsilon} .
\end{aligned}
$$

The first term on the right-hand side is the production term associated with turbulent motions occurring within a mean moisture gradient (following Stull's terminology, "the production term"). The second term represents the turbulent transport of $q_{t}$ variance, where $\bar{\rho}$ is the air density. The third and fourth terms are sedimentation source terms, where $V_{c}$ and $V_{r}$ are mass-weighted terminal fall speeds and $q_{c}$ and $q_{r}$ the mass mixing ratios for cloud droplets and raindrops. The fifth term represents eddy dissipation.

The growth of $q_{t}$ variance corresponds to positive $S_{q_{t}}$, which is, in general, an order of magnitude smaller than the terms on the right-hand side of Eq. (1). Figure 8a shows vertical profiles of the first four terms on the righthand side of Eq. (1) for Nd65 and Nd10 in the heightnormalized cloud and subcloud layers at $10 \mathrm{~h}$. The cloud layer extends from cloud base (lowest height where mean $q_{c} \geq 0.01 \mathrm{~g} \mathrm{~kg}^{-1}$ ) to the inversion height (mean height of $q_{t}=8 \mathrm{~g} \mathrm{~kg}^{-1}$ isosurface), and the subcloud layer extends from the surface to cloud base. Dissipation is not plotted 

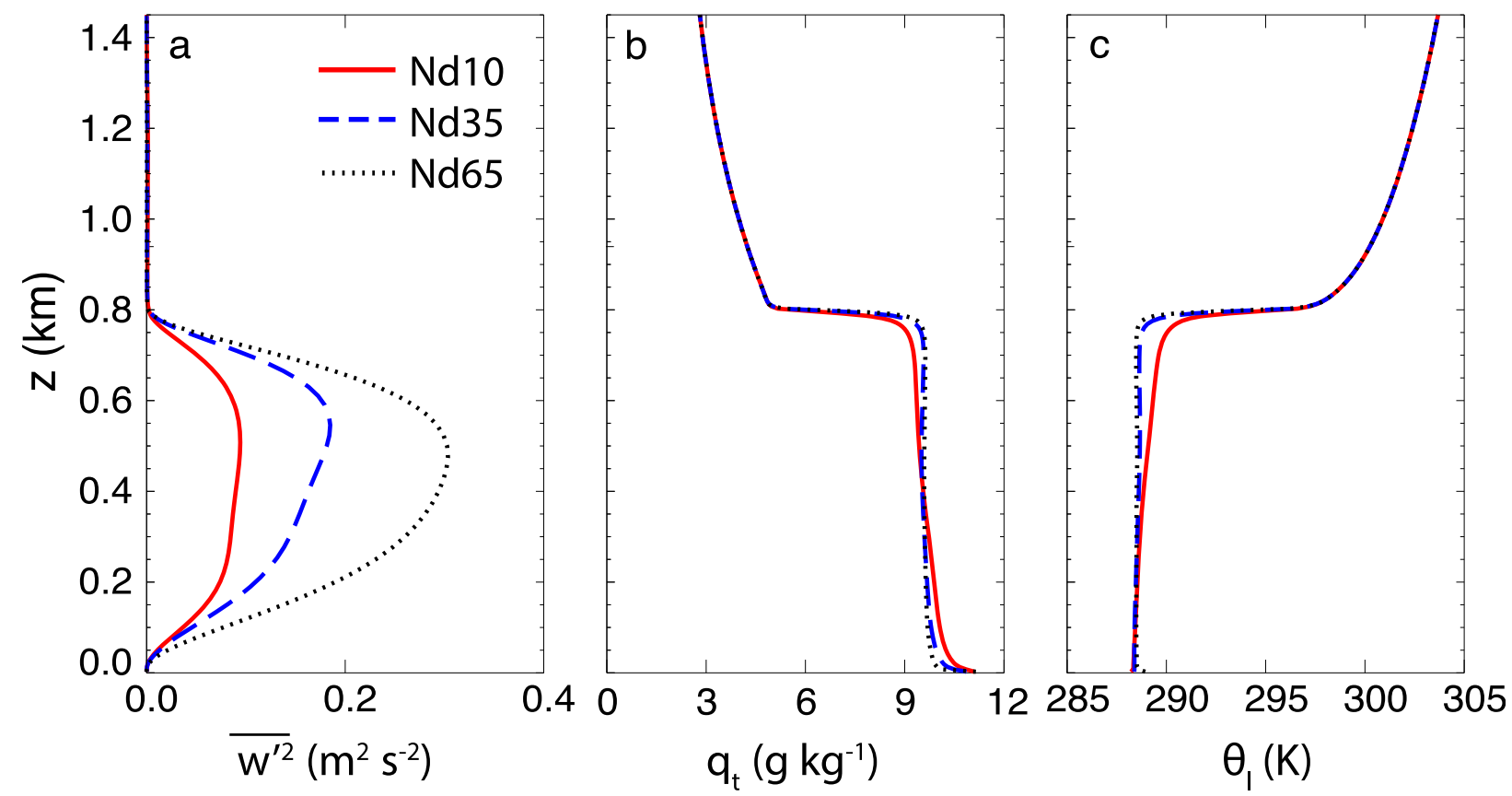

FIG. 6. Horizontally averaged profiles of (a) vertical wind velocity variance, (b) total water mixing ratio, and (c) liquid water potential temperature averaged over 9-11 h for Nd10, Nd35, and Nd65. Simulations as in Fig. 2.

because it diminishes rather than increases the variance. Except in the cloud layer of $\mathrm{Nd65}$, the production term is always positive in the STBL, pointing to the importance of the turbulent $q_{t}$ flux and stratification in increasing $q_{t}$ variance. As seen in Fig. 8b, the turbulent $q_{t}$ flux is positive for both cases, indicating that moisture and vertical winds are correlated at all altitudes, with updrafts moist and downdrafts dry such that the moisture flux flows down the $q_{t}$ gradient, carrying moist air from below and dry air from above. A comparison of Figs. $8 \mathrm{a}$ and $8 \mathrm{~b}$ suggests that the local $q_{t}$ gradient dominates the difference in the production terms between cases, signifying the key role of moisture stratification in determining $q_{t}$ variance. In the cloud layer of $\mathrm{Nd} 65$, the $q_{t}$ gradient becomes positive from cloud water increasing with height faster than water vapor decreases (Fig. 8c). This positive $q_{t}$ gradient facilitates moist downdrafts and dry updrafts, reducing $q_{t}$ variance in the cloud layer (Fig. 8a). This negative production term, however, is more than offset by the turbulent transport of $q_{t}$ variance from both above and below the cloud, where the production term is positive, and therefore does not prevent moisture variance from increasing in the cloud layer.

It is noteworthy that hydrometeor sedimentation also contributes to moisture variance. This effect is more evident in Nd10 where hydrometeors are larger and fall faster than in Nd65. In the cloud layer, cloud droplet sedimentation serves to increase moisture variance, while raindrop sedimentation tends to decrease it (Fig. 8a).
These can be interpreted in light of typical conditions in drizzling stratocumulus, where cloud water and mean droplet size both increase upward within the cloud, whereas drizzle water and mean drop size increase downward (e.g., Martin et al. 1994; Wood 2005; Wood et al. 2011). Larger cloud droplets above fall faster than smaller droplets below, leading to a vertical convergence of $q_{c}$, enhancing local $q_{t}$ and the horizontal $q_{t}$ variance. In contrast, the growth of raindrops downward through collision and coalescence results in a vertical divergence of $q_{r}$ and a reduction of the variance. The vertical divergence of $q_{r}$ is the largest near cloud top where the entrainment of dry and warm air is significant, hence rapid evaporation of raindrops. The counteracting effects of cloud droplet and raindrop sedimentation in the cloud layer largely offset one another in terms of $q_{t}$ variance. Below cloud base, raindrop sedimentation tends to slightly increase $q_{t}$ variance (Fig. 8a) because evaporation reduces the sizes of raindrops below cloud base and therefore causes a vertical convergence of rainwater. However, the raindrop sedimentation effect is insignificant compared to the production term in the subcloud layer (Fig. 8a).

The analysis of $S_{q_{t}}$ suggests that the production term is the leading factor in increasing moisture variance. Since moisture stratification is a prominent component of the production term, we further investigate its role in the next section by comparing $\mathrm{Nd10}$ (selected because it has the strongest drizzle) to $\mathrm{Nd} 10 \mathrm{H}$, which maintains mean $q_{t}$ and $\theta_{l}$ profiles in the STBL at their initial well-mixed states. 

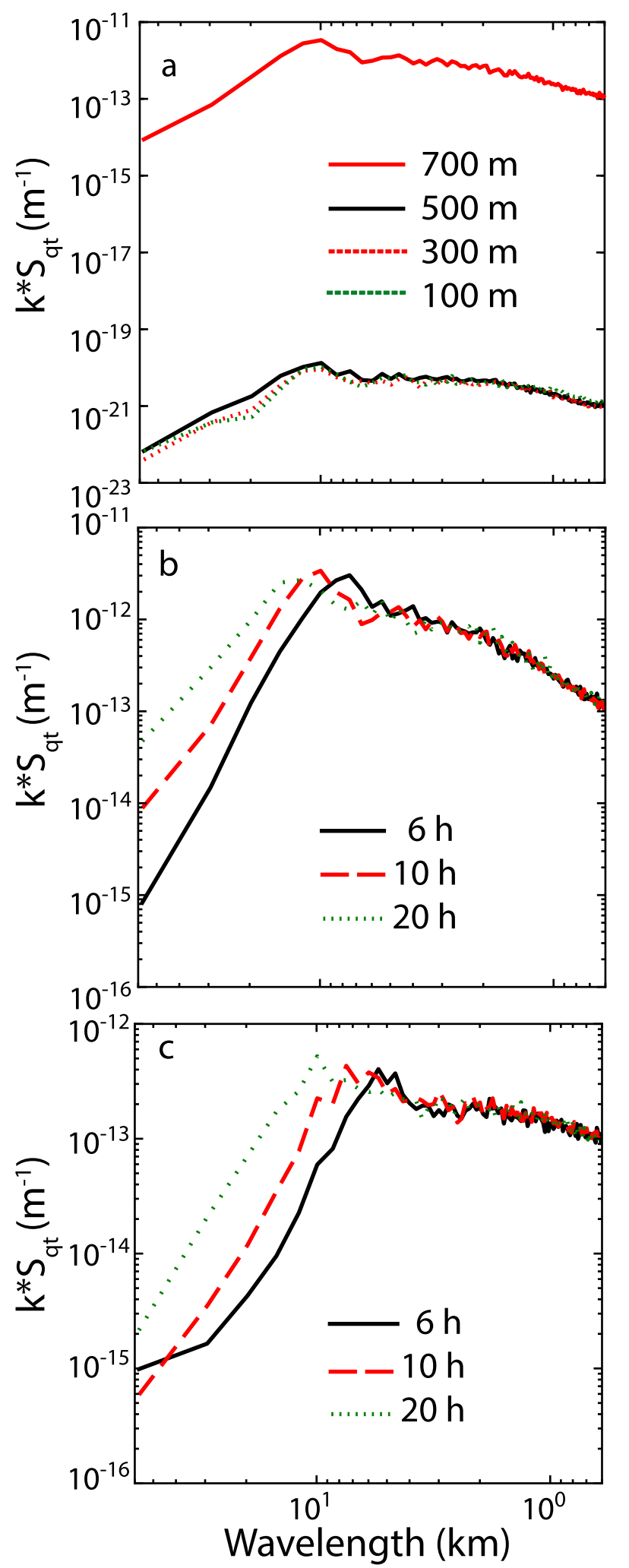

FIG. 7. Variance spectra of total water mixing ratio of (a) Nd10 at different levels at $10 \mathrm{~h}$, (b) Nd10 at $700 \mathrm{~m}$ at three times, and (c) Nd65 at $700 \mathrm{~m}$ at three times.

\section{Vertical moisture gradient and subcloud heterogeneous temperature perturbation}

A comparison of $\mathrm{Nd} 10$ and $\mathrm{Nd} 10 \mathrm{H}$ suggests that maintaining well-mixed $q_{t}$ and $\theta_{l}$ profiles serves to substantially reduce both the moisture variance throughout the STBL (Fig. 9) and its spectral length scale within the cloud layer (Fig. 10). The reduction of cloud scales is also evident in pseudoalbedo snapshots provided in Fig. 3e. This result confirms the importance of moisture stratification in broadening cloud scales. We stress that our nudging is horizontally uniform, which preserves horizontal variability, as is evident in the horizontal distribution of virtual potential temperature perturbation $\theta_{v}^{\prime}$ at $100 \mathrm{~m}$ in Fig. $11 \mathrm{~d}$ and its probability density function in Fig. 12.

Since moisture stratification is mainly attributable to raindrop evaporation that not only adds moisture to the air in the subcloud layer but, more importantly, stabilizes the boundary layer via evaporative cooling, which reduces vertical mixing and enhances the original moisture stratification, we further run an additional simulation in which raindrop evaporation is omitted from the Nd10 setup (Nd10NE; Table 1). As seen in Figs. $3 d$ and 10, the structural length scale for Nd10NE is comparable to that for $\mathrm{Nd} 10 \mathrm{H}$. Like $\mathrm{Nd} 10 \mathrm{H}$, eliminating raindrop evaporation reduces moisture stratification (Fig. 9a) and $q_{t}$ variance (Fig. 9b), and vertical stability is likewise diminished (not shown). But unlike the response to hard nudging in $\mathrm{Nd} 10 \mathrm{H}$, elimination of raindrop evaporation diminishes horizontal variability of $\theta_{v}$ in the subcloud layer (Figs. 11 and 12). In $\mathrm{Nd} 10 \mathrm{H}$, the distribution of $\theta_{v}$ variability near the surface is comparable to that in $\mathrm{Nd} 10$. That is, the $\mathrm{Nd} 10 \mathrm{H}$ cold pools are the same strength as in Nd10, but their spatial scales are dramatically reduced. From this, we conclude that convergence induced by cold pools is not a leading factor setting the horizontal scale of drizzling stratocumulus. Instead, it appears that near-surface density perturbations surprisingly respond to, rather than determine, the horizontal-scale moisture variability.

\section{Mechanism of mesoscale variability of drizzling stratocumulus}

The role of moisture stratification is further investigated via a hard-nudged variant of $\mathrm{Nd} 10$ where the initial $\theta_{l}$ profile is again well mixed but the initial $q_{t}$ profile in the STBL is now stratified rather than well mixed (Nd10HS; Table 1; Fig. 13). It is seen in Fig. 3f that mesoscale organization develops in Nd10HS. The horizontal scales at $10 \mathrm{~h}$ are even greater than for $\mathrm{Nd} 10$, and the increased rate of scale increase involves increased LWP for Nd10HS, which is a relationship we will consider at length in Part II of this 


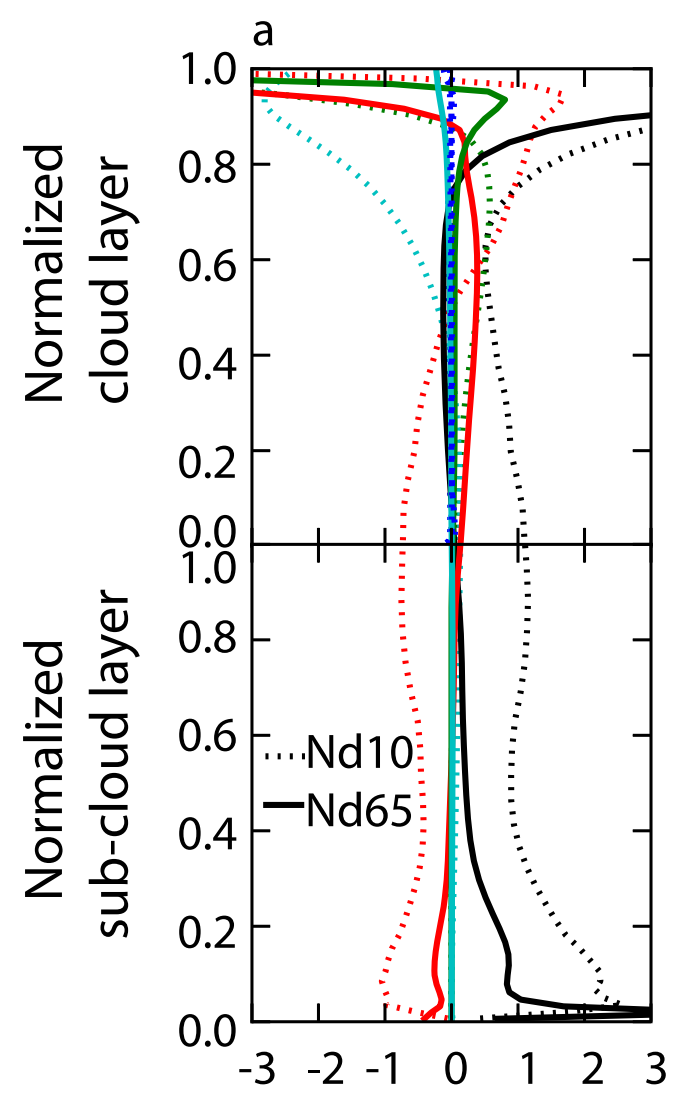

b

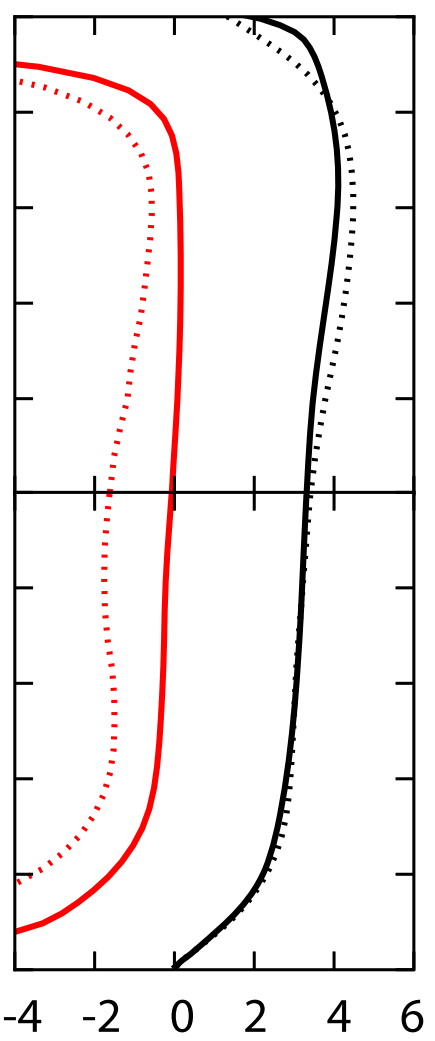

C

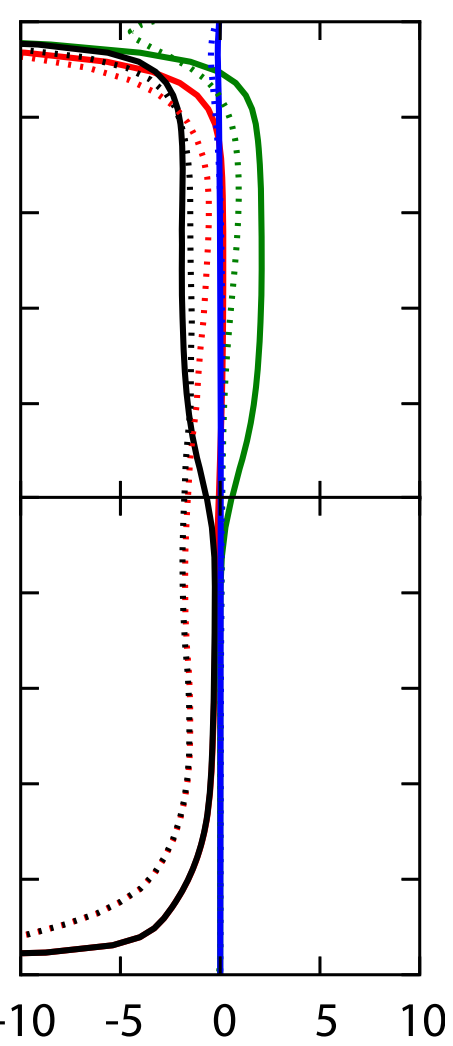

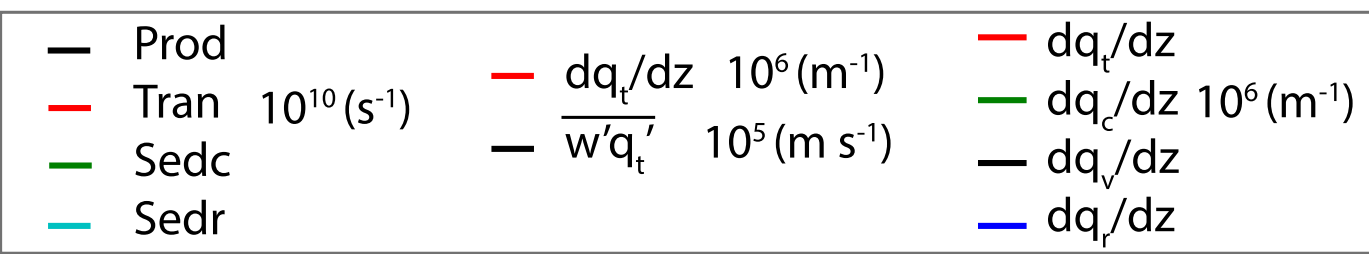

FIG. 8. (a) Profiles of Reynolds-averaged production (black), transport (red), and cloud and rain sedimentation (green and cyan) terms of Eq. (1); (b) horizontally averaged profiles of total water mixing ratio flux (black) and mean total water mixing ratio gradient (red); and (c) profiles of the vertical gradient of total water (red), cloud water (green), water vapor (black), and rainwater (blue) mixing ratio for Nd10 (dotted lines) and Nd65 (solid lines) at $10 \mathrm{~h}$. Setup of simulations described in main text and summarized in Table 1.

study; here, we focus on the emergence of larger scales from moisture stratification during the formative period of scale growth, at $6 \mathrm{~h}$, and examine the spectral decomposition of the production term in Eq. (1). Since Nd10H and the Nd10HS differ only in the initial (same as nudged) mean $q_{t}$ profiles, any differences for these two runs must ultimately derive from those differences. As seen in Fig. 14a, Nd10HS generates a bimodal production spectrum with peaks around 2 and $12 \mathrm{~km}$, whereas $\mathrm{Nd} 10 \mathrm{H}$ lacks the second peak at $\sim 12 \mathrm{~km}(\mathrm{Nd} 10 \mathrm{H})$. The peak at $\sim 2 \mathrm{~km}$ corresponds to turbulent mixing at a scale on the order of the STBL depth, while the occurrence of a second peak at $\sim 12 \mathrm{~km}$ is associated with imposed moisture stratification.

It is notable that the scale of the production term is effectively determined by the cospectra of moisture and vertical wind, rather than the moisture gradient alone, since the latter is computed from horizontally averaged moisture [Eq. (1)], which tends only to amplify or weaken the moisture contrast of a given scale but not to alter its horizontal geometry. It is thus implied that moisture stratification acts to promote upscale growth of length scales by modifying the cospectra. Our analysis below suggests that modification of the cospectra results from the dynamic response to moisture stratification in the boundary layer.

The adaptation of dynamics to moisture stratification is depicted in Fig. 14b. Although boundary layer turbulence in both cases ( $\mathrm{Nd} 10 \mathrm{H}$ and $\mathrm{Nd} 10 \mathrm{HS}$ ) is characterized by the most energetic eddies with scales on the order of the boundary layer depth, as is typical for the STBL (Hardy and Ottersten 1969; Schröter et al. 2005; 

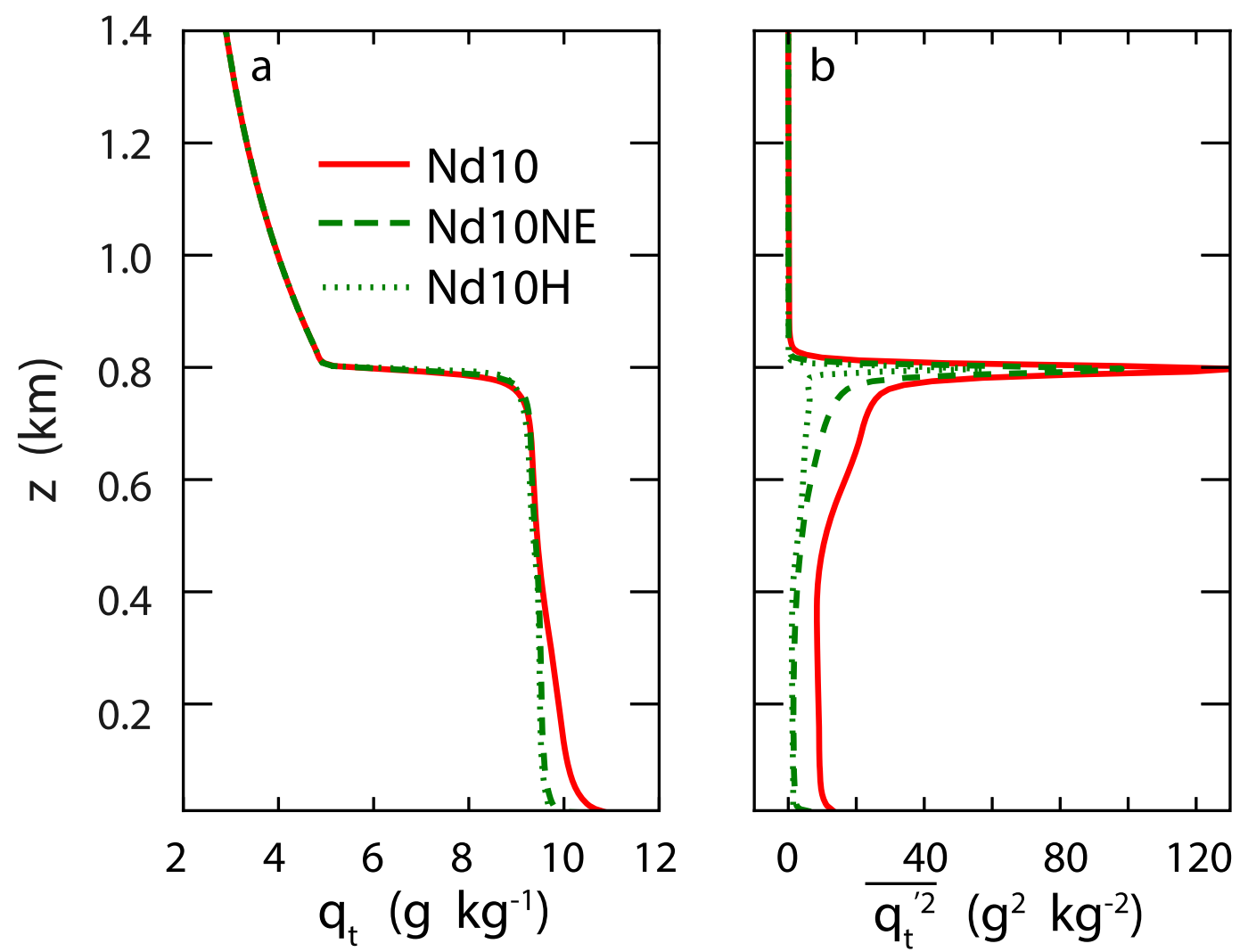

FIG. 9. Horizontally averaged profiles at $10 \mathrm{~h}$ of (a) total water mixing ratio and (b) total water mixing ratio variance for Nd10 (red solid line), without raindrop evaporation (Nd10NE; green dashed line), and with hard nudging ( $\mathrm{Nd} 10 \mathrm{H}$; green dotted line). Setup of simulations described in main text and summarized in Table 1.

de Roode et al. 2004), a secondary spectral peak at the mesoscale is evident for Nd10HS but not for $\mathrm{Nd} 10 \mathrm{H}$. The same association of moisture stratification and mesoscale vertical wind variance is evident in our simulations without hard nudging, as a mesoscale peak occurs only for Nd10 (not shown). We hypothesize that greater vertical wind variance at the mesoscale serves as a forcing, increasing the cospectra of moisture and vertical wind at the mesoscale and ultimately affecting the scales of moisture variance (Fig. 14c).

To better understand the impact of thermodynamics on dynamics, we next examine the contributions to buoyancy $b$ as cast in the DHARMA model,

$$
b=\frac{g}{\theta_{0}}\left(\theta+\theta_{0} \varepsilon q_{v}-\theta_{0} q_{c}-\theta_{0} q_{r}\right)
$$

where $\varepsilon=R_{v} / R_{d}-1, R_{d}$ and $R_{v}$ are the gas constants for dry air and water vapor, respectively, $\theta_{0}$ is base-state potential temperature, and $g$ is gravitational acceleration. Given that temperature and moisture both contribute to buoyancy, there are at least two mechanisms by which buoyancy may increase in an updraft as a result of moisture stratification: (i) the direct increase of water vapor and (ii) the additional latent heating from condensation of more water vapor. Inspired by Shao and Randall (1996) and Müller and Chlond (1996), we speculate that increased buoyancy in updrafts entails longer horizontal distances traversed near cloud top before air parcels lose their buoyancy, thereby increasing the horizontal scales of moisture variance. Our simulation results presented below suggest that the second (latent heating) is essential for drizzling stratocumulus organization.

The impact of moisture on buoyancy is examined by neglecting the last three terms in Eq. (2) from the Nd10HS setup (Nd10HS-NoMoist). As seen in Fig. 14, eliminating the direct contributions of moisture to buoyancy fails to suppress increased vertical wind variance at the mesoscale, and the horizontal scale of $q_{t}$ variability in the cloud layer remains large. This negative result implies that the direct impacts of water vapor and condensate loading on mesoscale dynamics are minor relative to those of latent heating in the cloud layer. We note that these mesoscale peaks of Nd10HS and Nd10HS-NoMoist are retained (although the scale increase is slower) in further sensitivity tests in which the initial stability 


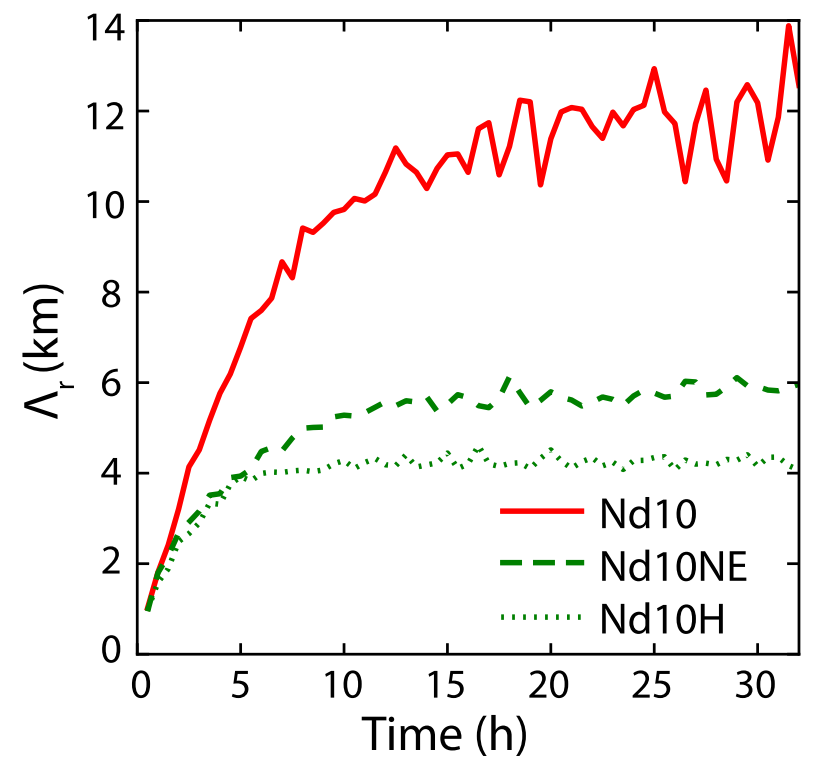

FIG. 10. Spectral length scale of total water mixing ratio variance at $700 \mathrm{~m}$ for $\mathrm{Nd} 10$ (red solid line), without raindrop evaporation (Nd10NE; green dashed line), and with hard nudging $(\mathrm{Nd} 10 \mathrm{H}$; green dotted line). Simulations as in Fig. 9.

(in terms of $\theta_{v}$ gradient) is modified correspondingly such that initial stability is preserved prior to, or after, the release of latent heat resulting from initial cloud formation (not shown).

The association of buoyancy fluxes with drizzle intensity in the baseline simulations is shown in Fig. 15, where Nd10 exhibits greater top-percentile $\overline{w^{\prime} \theta_{v}^{\prime}}$ (averaging over columns with peak $w^{\prime} \theta_{v}^{\prime}$ in the top percentile of column peak $\left.w^{\prime} \theta_{v}^{\prime}\right)$ relative to $\mathrm{Nd} 65$ in the cloud layer, although its mean $\overline{w^{\prime} \theta_{v}^{\prime}}$ is substantially smaller. This discrepancy between mean and extreme profiles suggests that the convection of heavily drizzling stratocumulus is more intermittent and thus in places more vigorous than that of lightly drizzling stratocumulus, consistent with our finding that moisture stratification modifies the moisture variability scale in the STBL by locally enhancing buoyancy in updrafts predominantly via increased latent heating.

\section{Discussion and conclusions}

Drizzle effects on the development of stratocumulus mesoscale organization are investigated through $32-\mathrm{h}$ eddy-permitting simulations using a $60 \times 60 \times 1.5 \mathrm{~km}^{3}$ domain. To simplify analysis, simulations use fixed surface heat fluxes, and a nearly constant inversion height is maintained through nudging. Our results indicate that drizzle is associated with an increase in moisture variability scales. This result also holds in the presence of interactive surface fluxes (not shown). By analyzing

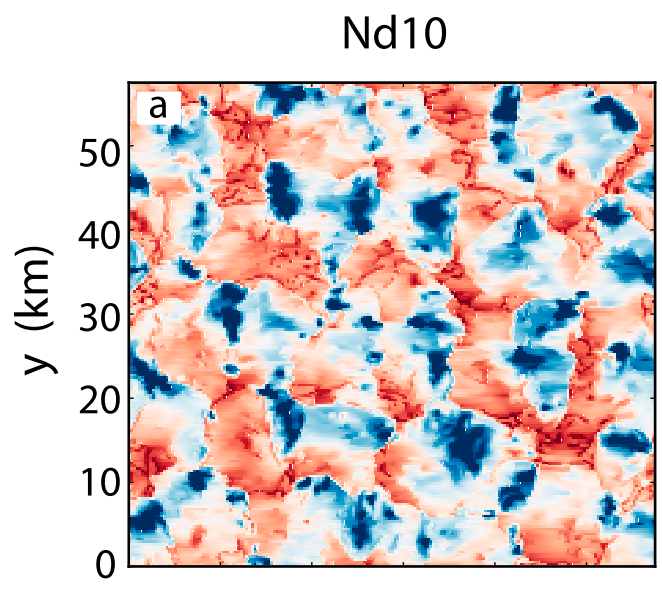

Nd10NE

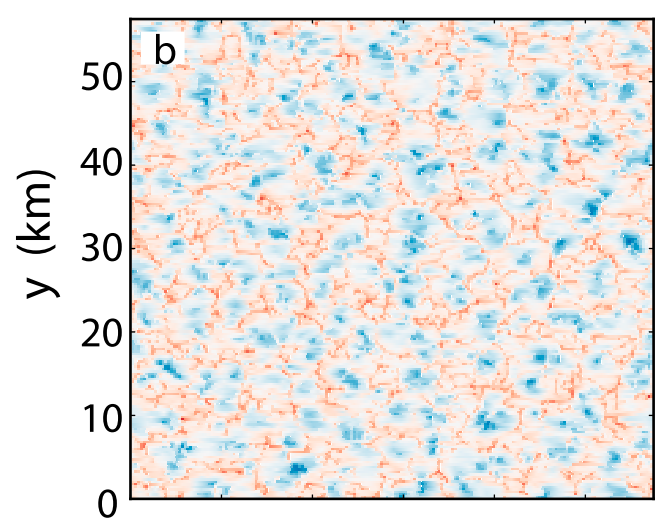

$\mathrm{Nd} 10 \mathrm{H}$

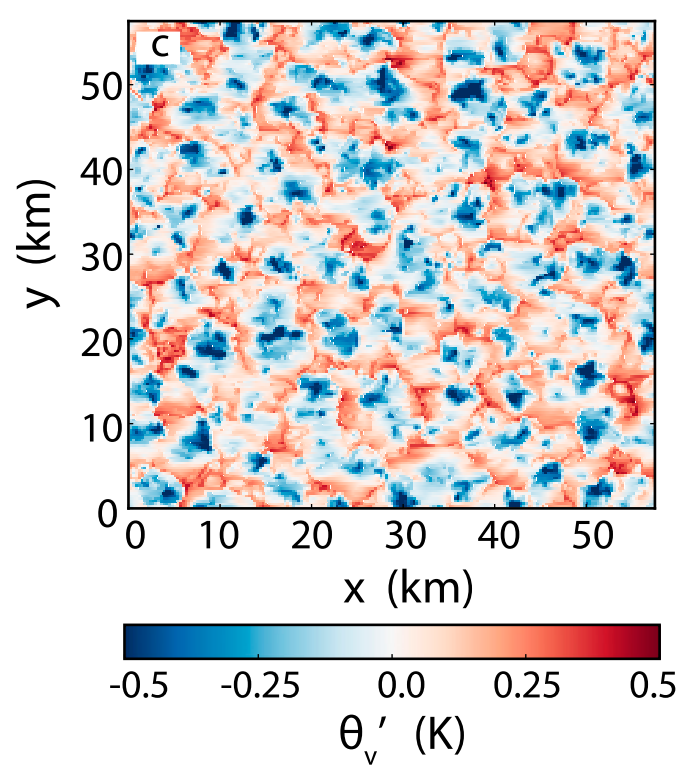

FIG. 11. Snapshots of virtual potential temperature perturbation at altitude $100 \mathrm{~m}$ and time $10 \mathrm{~h}$ for (a) Nd10, (b) Nd10NE, and (c) $\mathrm{Nd} 10 \mathrm{H}$. 


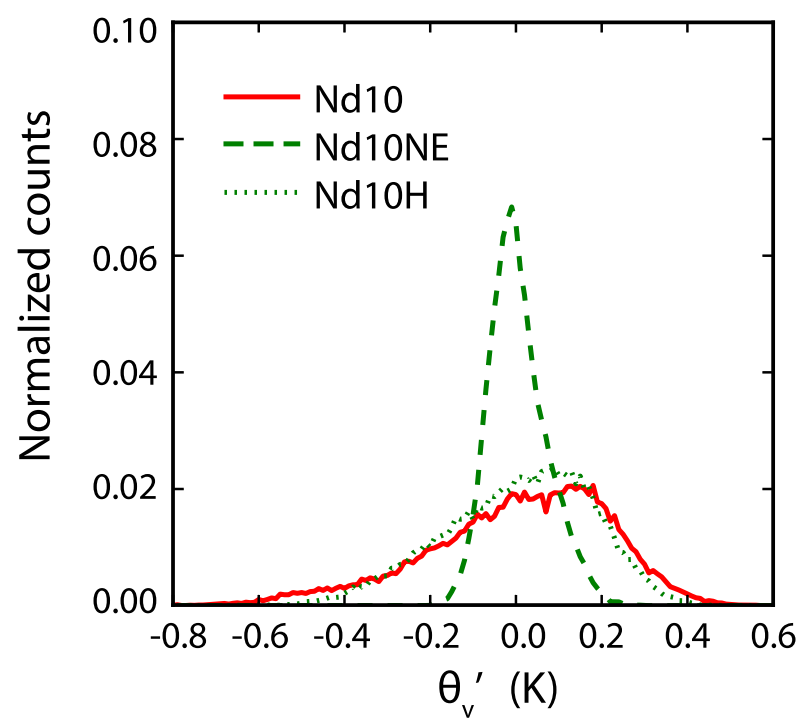

FIG. 12. Distribution of virtual potential temperature perturbation at altitude $100 \mathrm{~m}$ and time $10 \mathrm{~h}$ for $\mathrm{Nd} 10$ (red solid line), without raindrop evaporation (Nd10NE; green dashed line), and with hard nudging (Nd10H; green dotted line). Simulations as in Fig. 9.

terms in the prognostic equation for resolved moisture variance, we find that moisture stratification developed under drizzling conditions plays a key role in increasing the moisture variance. We note that while boundary layer stability is a necessary condition for mesoscale organization of drizzling stratocumulus because it allows moisture stratification to develop, it is not sufficient to drive such organization in the absence of a vertical

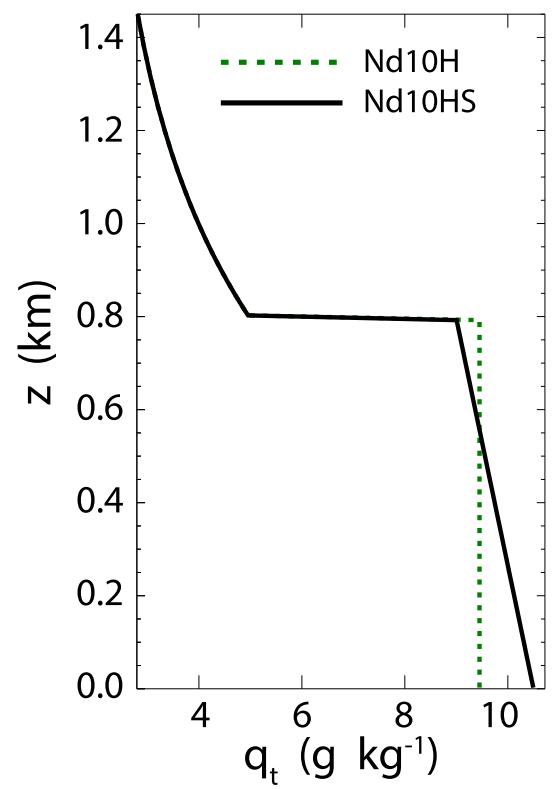

FIG. 13. Initial $q_{t}$ profiles for $\mathrm{Nd} 10 \mathrm{H}$ and $\mathrm{Nd} 10 \mathrm{HS}$. Setup of simulations as indicated in legend, described in main text, and summarized in Table 1.
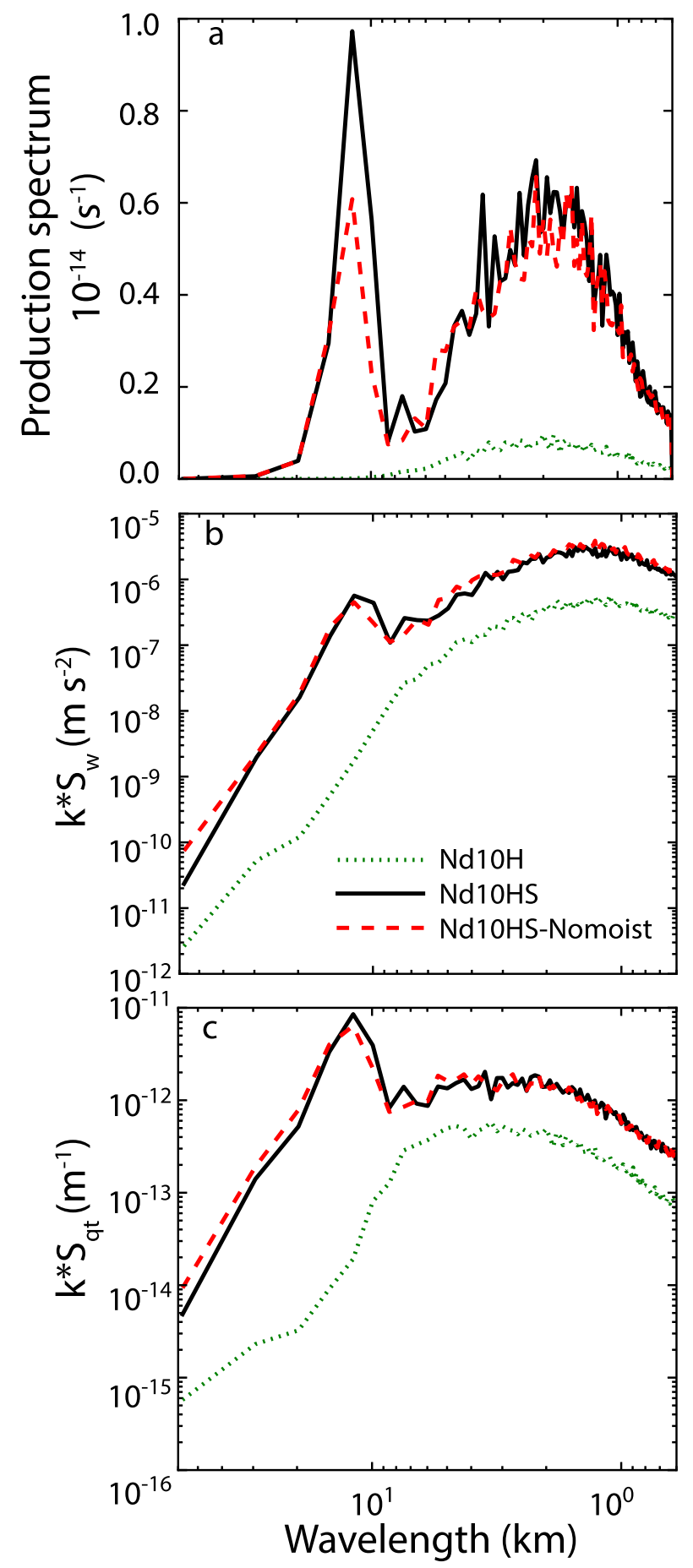

FIG. 14. (a) Spectral decomposition of the production term in Eq. (1), (b) variance spectra of vertical wind velocity, and (c) variance spectra of total water mixing ratio at altitude $700 \mathrm{~m}$ and time $10 \mathrm{~h}$. Setup of simulations as indicated in legend, described in main text, and summarized in Table 1.

moisture gradient (evident in further sensitivity tests not shown in which only moisture or temperature are hard nudged). 

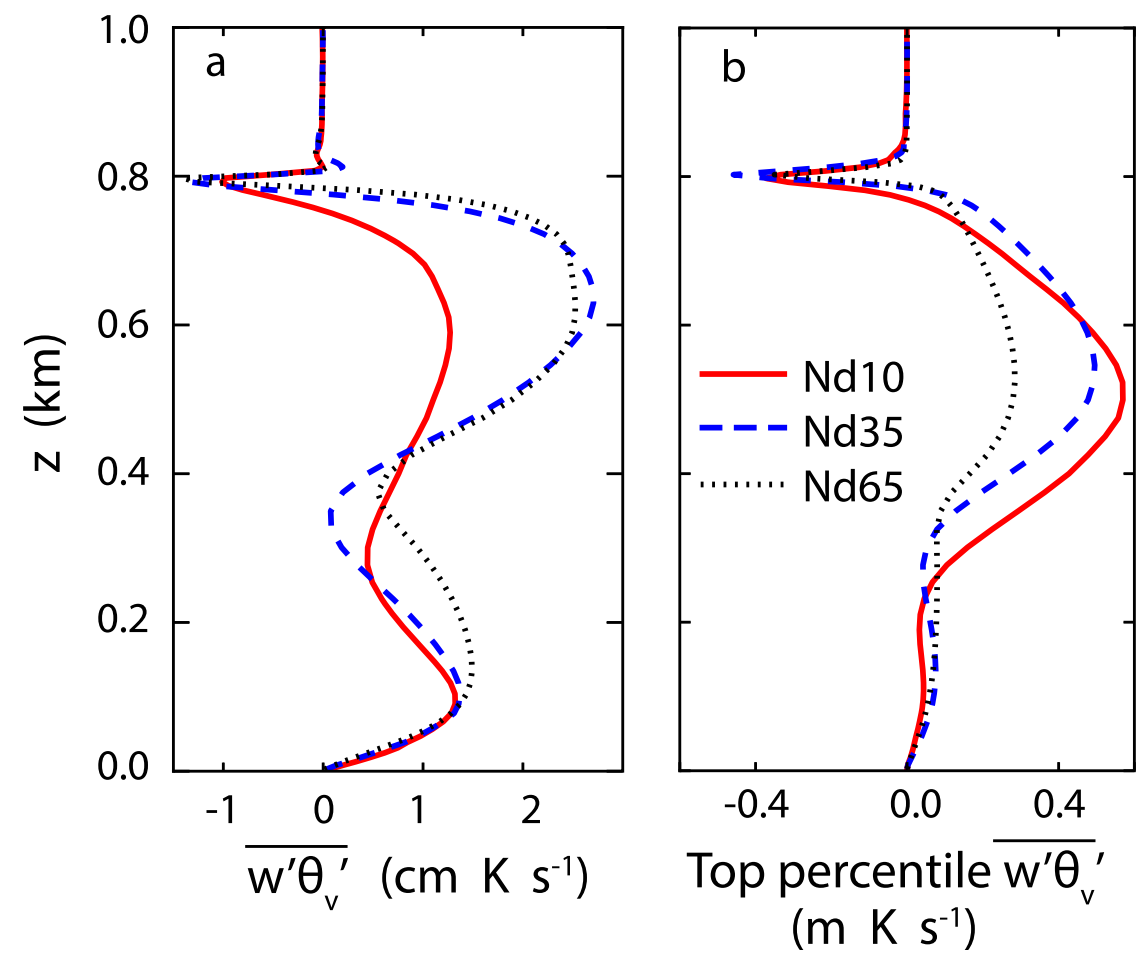

FIG. 15. Profiles at $10 \mathrm{~h}$ of (a) horizontally averaged and (b) top-percentile peak buoyancy flux. Simulations as in Fig. 2.

In the analysis presented in section 5, we demonstrate that the dynamic response to evaporative cooling and moistening associated with precipitation surprisingly responds to the mesoscale variability of moisture rather than determining it. That is, drizzling stratocumulus moist cold pools are localized features rather than propagating density current below deep convective or shallow cumulus clouds (e.g., Xue et al. 2008; Lima and Wilson 2008; Böing et al. 2012; Seifert and Heus 2013). Stratocumulus cold pools differ from trade wind cumulus and deep convection cold pools in the sense that the latter generally exhibit a pronounced dry core, whereas stratocumulus cold pools are generally moist below cloud in regions of active precipitation (e.g., vanZanten and Stevens 2005; Savic-Jovcic and Stevens 2008; Seifert and Heus 2013). It is likely that a strong inversion capping the STBL prevents deep mixing of freetropospheric air into it, inhibiting the development of cool and dry downdrafts. Differences between precipitation regimes in stratocumulus and shallow cumulus would likely be a fruitful target for further studies.

Analysis of the prognostic equation for moisture variance shows that cloud droplet sedimentation provides vertical moisture convergence that increases moisture variance in the cloud layer, whereas raindrop sedimentation tends to decrease the in-cloud moisture variance through vertical moisture divergence. However, the net effect of cloud droplet and raindrop sedimentation on moisture variability scales in the cloud layer is modest because of their counteracting tendencies. Below cloud base, raindrop sedimentation tends to slightly increase moisture variance from net evaporation, but the impact is negligible compared to the production term associated with moisture stratification.

We note that there are limits to increases in horizontal scales of organization that can be induced by decreasing droplet concentrations, which is likely attributable to a negative feedback between drizzle and liquid water path, as discussed in appendix C.

Our results suggest that moisture stratification increases cloud organizational scales through dynamics. The moisture stratification increases local moisture supply into the cloud, which then favors greater positive buoyancy predominantly through latent heating. This result is consistent with the idea that air parcels with greater buoyancy pass longer distances before losing their buoyancy, favoring greater horizontal scales. This concept likely explains the sizable horizontal scale of drizzling stratocumulus with low LWP as investigated here for variations on a single case study. We acknowledge that moisture stratification is surely not the only factor contributing to mesoscale organization of stratocumulus. 
For instance, it has been shown by de Roode et al. (2004) that cloud-top radiative cooling also contributes to cell broadening, which will be explored in Part II of this study (for nondrizzling conditions). Additionally, to the extent that greater LWP results from more condensation rather than less drizzle, an increased latent heat release in updrafts will result in horizontal cloud scales increasing with LWP. Also, consistent with the observational analysis of Wood and Hartmann (2006), we find horizontal cloud scale to increase with boundary layer depth for this drizzling stratocumulus case when we control for LWP by reducing humidity (not shown).

Whereas here, we analyze simulations under artificially controlled conditions to identify the specific factors that increase organizational scales, we note that interaction of cellular organization states with the environmental conditions that influence them, as investigated by Yamaguchi and Feingold (2015), have been neglected here. Simulations in a free-running microphysical and dynamical environment with diurnal variability are necessary to provide a fuller understanding of mesoscale organization in natural cloud systems.

Acknowledgments. This research was funded by the NASA ORACLES project and the DOE ASR program (Grant DE-SC0013489). Resources supporting this work were provided by the NASA High-End Computing (HEC) Program through the NASA Advanced Supercomputing (NAS) Division at Ames Research Center. We thank Chris Bretherton and three anonymous reviewers for helpful suggestions. All data of this study are available from the corresponding author (xiaoliz@uw.edu).

\section{APPENDIX A}

\section{Simulations without Nudging}

Fig. A1 shows three baseline simulations where no nudging is applied (Nd10R, Nd35R, and Nd65R). To the extent that the moisture scales of Nd10R are greatest for the first $15 \mathrm{~h}$, our nudging approach does not introduce confounding artifacts. The reduction of Nd10R moisture scale after $15 \mathrm{~h}$ is mainly caused by dramatic reduction of cloud water as a result of the boundary layer warming from entrainment of overlying air: at the end of $\mathrm{Nd} 10 \mathrm{R}$, the LWP is less than $10 \mathrm{~g} \mathrm{~m}^{-2}$, and cloud thickness is less than $300 \mathrm{~m}$ (Figs. A1b,c). The substantial reduction of cloud water inhibits latent heating and therefore hampers cell broadening. Consistent with the Nd5 simulation presented in appendix $\mathrm{C}$, this result suggests that the stratocumulus organization scale does not increase with ever-increasing precipitation. Once desiccation of the cloud layer from precipitation overcomes its moisture supply, cloud scale is likely to be reduced.

\section{APPENDIX B}

\section{Definitions of a Characteristic Length Scale}

A characteristic length scale can be defined in a number of ways. One obvious definition is the wavenumber at which the spectral peak is located. This method is most suitable for large datasets (e.g., Wood and Hartmann 2006). However, for a single time slice of a simulation with 40000 horizontal grid points, this definition suffers from statistical noise that depend on the discretization used for the fast Fourier transforms (Fig. B1). Under such conditions, methods based on a weighted integral of the spectrum such as proposed by de Roode et al. (2004), described in the main text, are more robust. Pino et al. (2006) proposed a slightly different method that calculates an average wavenumber weighted by spectral energy: $k_{r}=\int_{0}^{\infty} S_{\psi}(k) k^{a} d k /$ $\int_{0}^{\infty} S_{\psi}(k) d k$, where $S_{\psi}(k)$ is the spectral density of $\psi$ variance for wavenumber $k$. The parameter $a$ influences the contribution of wavenumbers away from the spectral peak; Pino et al. (2006) found that $a=-1$ is the most appropriate (Pope 2000; Jonker and Vilà-Guerau de Arellano 2005). As seen in Fig. B1, both alternative approaches capture the trend of the length scale, but that of de Roode et al. (2004) has the advantage of better matching the spectral peak.

\section{APPENDIX C}

\section{Open-Cell Features and Low $N_{d}$}

To show that Nd10 is indicative of an open-cell drizzling case, rather than simply increased gaps between cloudy regions, we plot the snapshots of pseudoalbedo for Nd10 at times of 10, 20, and 30h (Figs. Cla-c), where the open-cell features with bright cloudy edges are clearly observed. The open-cell feature becomes more evident at $N_{d}=5 \mathrm{~cm}^{-3}$ (Nd5; Figs. Cld-f) from stronger drizzle and more reduction in LWP (Figs. $\mathrm{Cl}$ b and $\mathrm{Clc}$ ). We note, however, that despite the stronger drizzle, the role of moist cold pools in modifying the spatial distribution of clouds remains insignificant for Nd5. In fact, the temperature spatial inhomogeneity tends to weaken at such a small droplet concentration because not only do larger drizzle drops evaporate less in the subcloud layer (Dawson et al. 2010), but also, the precipitation rate is limited by a negative feedback between 

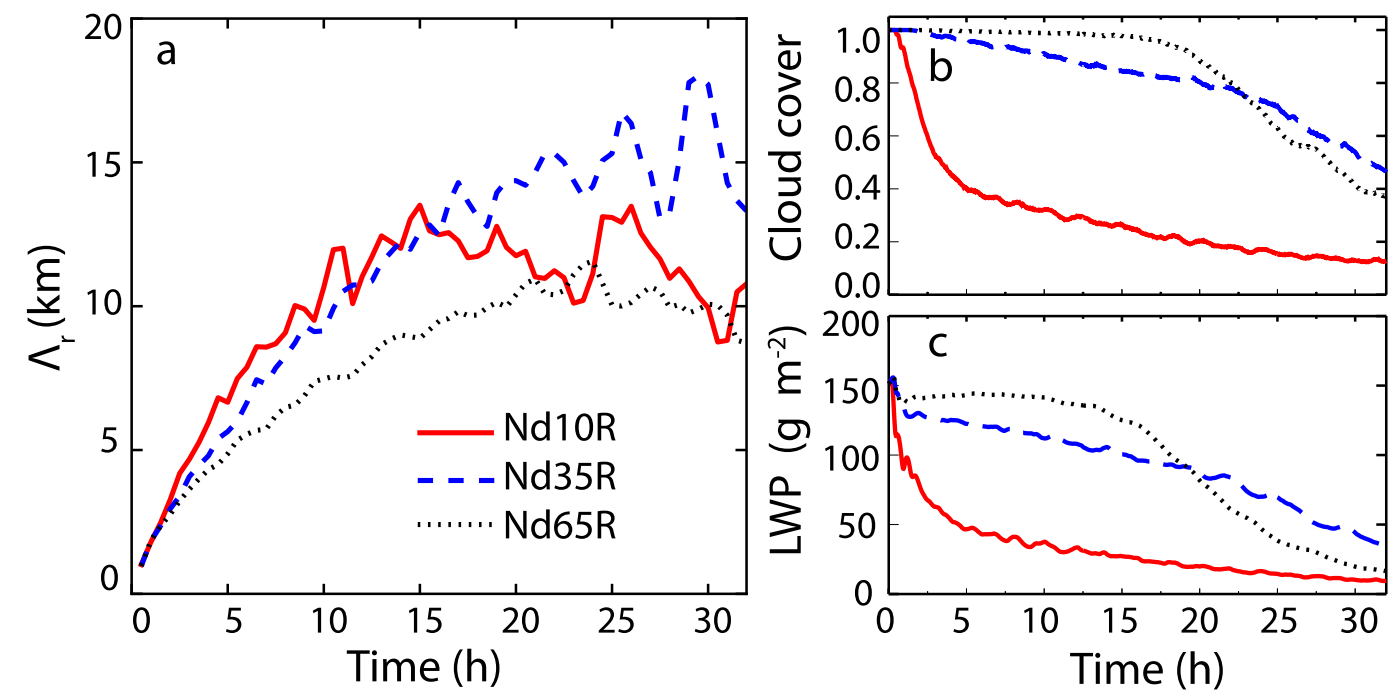

FIG. A1. Temporal evolution of (a) spectral length scale of total water mixing ratio variance at $700 \mathrm{~m}$, (b) cloud cover, and (c) LWP for simulations (as indicated in legend) without nudging (Nd10R, Nd35R, and Nd65R) but otherwise identical to $\mathrm{Nd} 10, \mathrm{Nd} 35$, and $\mathrm{Nd} 65$.

precipitation and LWP in which increasing drizzle tends to decrease LWP, which in turn tends to hinder drizzle increase. As seen in Fig. C2a, the cloud scales are marginally smaller in $\mathrm{Nd} 5$ relative to $\mathrm{Nd} 10$, which is attributable to the considerable reduction in LWP reducing cloud-top longwave heating as well as latent heating. While the specific optimal $N_{d}$ that leads to the largest scales surely depends on model formulation and setup, our result suggests that there is a limit to the scales induced by progressively decreasing droplet concentrations in stratocumulus. However, the cloud scales for the heavily drizzling stratocumulus of $\mathrm{Nd} 5$ are still greater than for the lightly drizzling stratocumulus of Nd65, consistent with the importance of moisture stratification for increasing organization length scales.
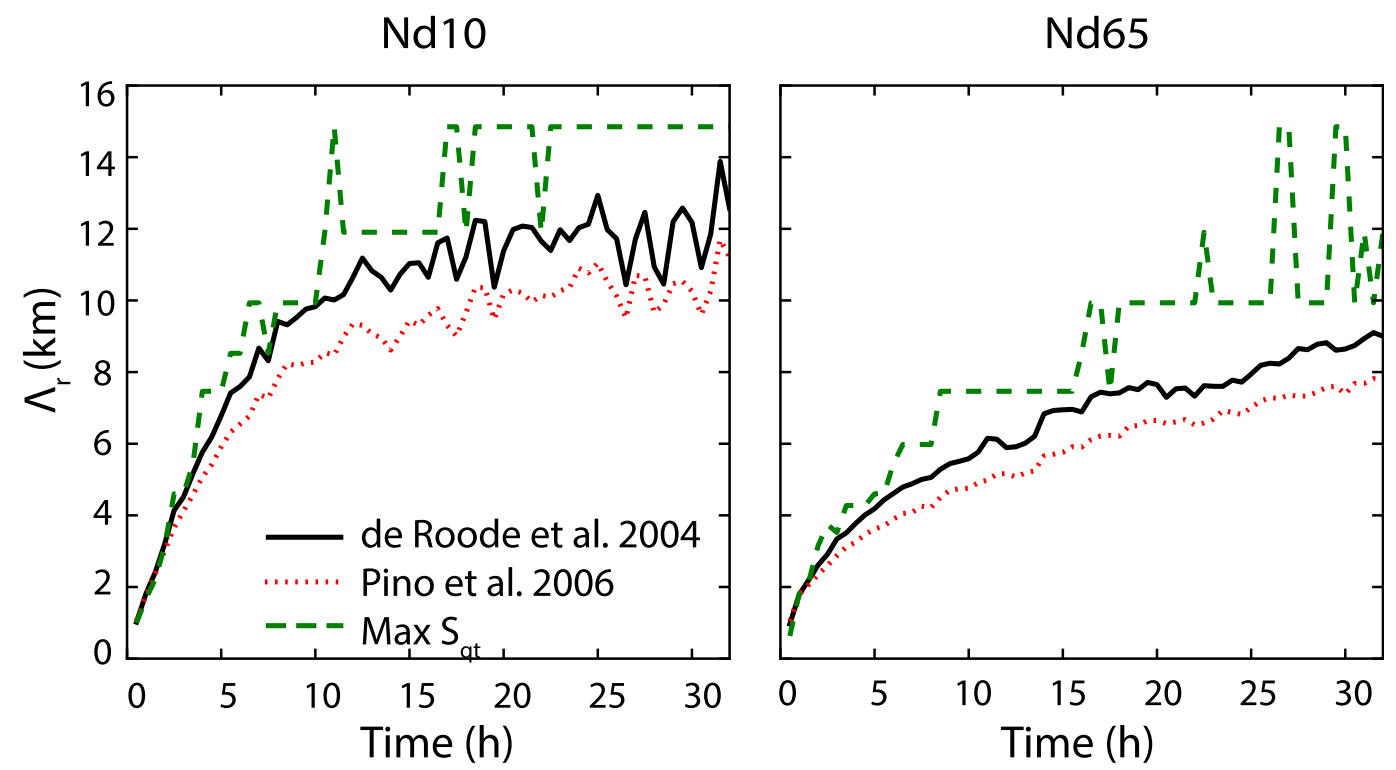

FIG. B1. Temporal evolution of total water mixing ratio variance length scale at $700 \mathrm{~m}$ computed by different approaches, in which "Max $S_{q_{t}}$ " corresponds to the wavelength of the spectral peak and the other methods are described in appendix B. Simulations as in Fig. 8. 

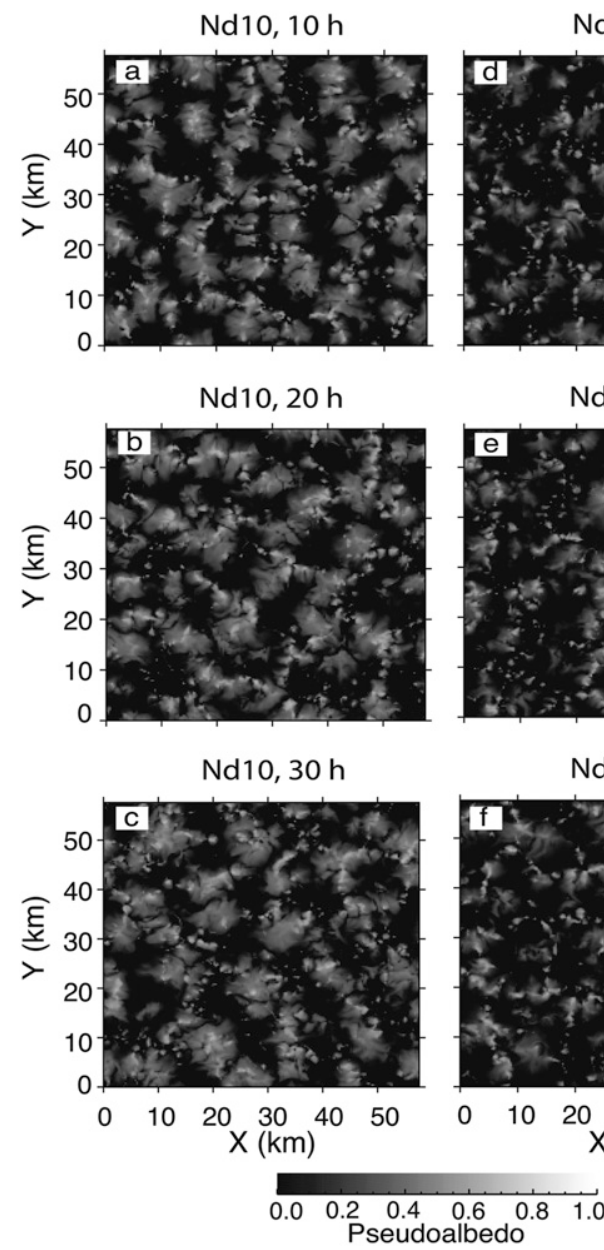

FIG. C1. Snapshots of pseudoalbedo for (a)-(c) Nd10 and (d)-(f) Nd5 at (a),(d) 10, (b),(e) 20, and (c),(f) $30 \mathrm{~h}$. Cloud droplet concentrations are 5 and $10 \mathrm{~cm}^{-3}$ in simulations $\mathrm{Nd} 5$ and $\mathrm{Nd} 10$.
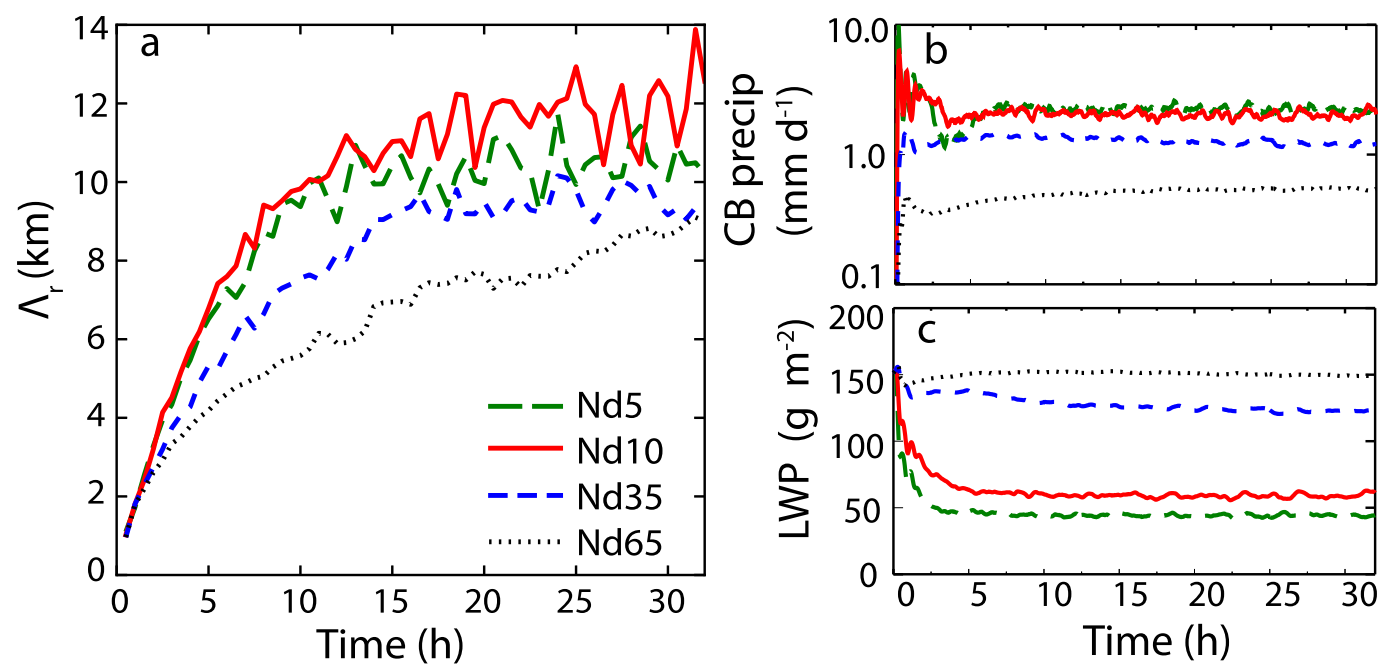

FIG. C2. Temporal evolution of (a) total water mixing ratio variance length scale at $700 \mathrm{~m}$, (b) precipitation rate at cloud base, and (c) LWP. Simulations as indicated in legend. 


\section{REFERENCES}

Ackerman, A. S., O. B. Toon, and P. V. Hobbs, 1993: Dissipation of marine stratiform clouds and collapse of the marine boundary layer due to the depletion of cloud condensation nuclei by clouds. Science, 262, 226-229, https://doi.org/10.1126/ science.262.5131.226.

- M. P. Kirkpatrick, D. E. Stevens, and O. B. Toon, 2004: The impact of humidity above stratiform clouds on indirect aerosol climate forcing. Nature, 432, 1014-1017, https://doi.org/ 10.1038/nature03174.

—, and Coauthors, 2009: Large-eddy simulations of a drizzling, stratocumulus-topped marine boundary layer. Mon. Wea. Rev., 137, 1083-1110, https://doi.org/10.1175/2008MWR2582.1.

Agee, E. M., T. S. Chen, and K. E. Dowell, 1973: A review of mesoscale cellular convection. Bull. Amer. Meteor. Soc., 54, 1004-1012, https://doi.org/10.1175/1520-0477(1973)054<1004: AROMCC $>2.0 . \mathrm{CO} ; 2$.

Albrecht, B. A., C. S. Bretherton, D. Johnson, W. H. Scubert, and A. S. Frisch, 1995: The Atlantic Stratocumulus Transition ExperimentASTEX. Bull. Amer. Meteor. Soc., 76, 889-904, https://doi.org/ 10.1175/1520-0477(1995)076<0889:TASTE $>2.0 . C O ; 2$.

Atkinson, B. W., and J. W. Zhang, 1996: Mesoscale shallow convection in the atmosphere. Rev. Geophys., 34, 403-431, https:// doi.org/10.1029/96RG02623.

Berner, A. H., C. S. Bretherton, and R. Wood, 2011: Large-eddy simulation of mesoscale dynamics and entrainment around a pocket of open cells observed in VOCALS-REx RF06. Atmos. Chem. Phys., 11, 10 525-10 540, https://doi.org/ 10.5194/acp-11-10525-2011.

Bohren, C. F., 1987: Multiple scattering of light and some of its observable consequences. Amer. J. Phys., 55, 524-533, https:// doi.org/10.1119/1.15109.

Böing, S. J., H. J. Jonker, A. P. Siebesma, and W. W. Grabowski, 2012: Influence of the subcloud layer on the development of a deep convective ensemble. J. Atmos. Sci., 69, 2682-2698, https://doi.org/10.1175/JAS-D-11-0317.1.

Bony, S., and J. L. Dufresne, 2005: Marine boundary layer clouds at the heart of tropical cloud feedback uncertainties in climate models. Geophys. Res. Lett., 32, L20806, https://doi.org/ 10.1029/2005GL023851.

- , and Coauthors, 2006: How well do we understand and evaluate climate change feedback processes? J. Climate, 19 , 3445-3482, https://doi.org/10.1175/JCLI3819.1.

Bretherton, C. S., T. Uttal, C. W. Fairall, and S. E. Yuter, 2004: The EPIC 2001 stratocumulus study. Bull. Amer. Meteor. Soc., 85 , 967-977, https://doi.org/10.1175/BAMS-85-7-967.

_ J. Uchida, and P. N. Blossey, 2010: Slow manifolds and multiple equilibria in stratocumulus-capped boundary layers. J. Adv. Model. Earth Syst., 2 (14), https://doi.org/10.3894/ JAMES.2010.2.14

Comstock, K. K., C. S. Bretherton, and S. E. Yuter, 2005: Mesoscale variability and drizzle in southeast Pacific stratocumulus. J. Atmos. Sci., 62, 3792-3807, https://doi.org/10.1175/ JAS3567.1.

- S. E. Yuter, R. Wood, and C. S. Bretherton, 2007: The threedimensional structure and kinematics of drizzling stratocumulus. Mon. Wea. Rev., 135, 3767-3784, https://doi.org/ 10.1175/2007MWR1944.1.

Dawson, D. T., M. Xue, J. A. Milbrandt, and M. K. Yau, 2010: Comparison of evaporation and cold pool development between single-moment and multimoment bulk microphysics schemes in idealized simulations of tornadic thunderstorms.
Mon. Wea. Rev., 138, 1152-1171, https://doi.org/10.1175/ 2009MWR2956.1.

de Roode, S. R., P. G. Duynkerke, and H. J. Jonker, 2004: Largeeddy simulation: How large is large enough? J. Atmos. Sci., 61, 403-421, https://doi.org/10.1175/1520-0469(2004)061<0403: LSHLIL $>2.0 . \mathrm{CO} ; 2$.

Dörnbrack, A., 1997: Broadening of convective cells. Quart. J. Roy. Meteor. Soc., 123, 829-847, https://doi.org/10.1002/qj.49712354003.

Feingold, G., R. Boers, B. Stevens, and W. R. Cotton, 1997: A modeling study of the effect of drizzle on cloud optical depth and susceptibility. J. Geophys. Res., 102, 13 527-13 534, https:// doi.org/10.1029/97JD00963.

I. Koren, H. Wang, H. Xue, and W. A. Brewer, 2010: Precipitation-generated oscillations in open cellular cloud fields. Nature, 466, 849-852, https://doi.org/10.1038/ nature 09314.

Frisch, A. S., C. W. Fairall, and J. B. Snider, 1995: Measurement of stratus cloud and drizzle parameters in ASTEX with a $\mathrm{K}_{\alpha}$-band Doppler radar and a microwave radiometer. J. Atmos. Sci., 52, 2788-2799, https://doi.org/10.1175/ 1520-0469(1995)052<2788:MOSCAD > 2.0.CO;2.

Green, B. W., and F. Zhang, 2015: Numerical simulations of Hurricane Katrina (2005) in the turbulent gray zone. J. Adv. Model. Earth Syst., 7, 142-161, https://doi.org/10.1002/2014MS000399.

Hardy, K. R., and H. Ottersten, 1969: Radar investigations of convective patterns in the clear atmosphere. J. Atmos. Sci., 26, 666-672, https://doi.org/10.1175/1520-0469(1969)26<666: RIOCPI $>2.0 . \mathrm{CO} ; 2$.

Hartmann, D. L., M. E. Ockert-Bell, and M. L. Michelsen, 1992: The effect of cloud type on Earth's energy balance: Global analysis. J. Climate, 5, 1281-1304, https://doi.org/ 10.1175/1520-0442(1992)005<1281:TEOCTO > 2.0.CO;2.

Jones, C. R., C. S. Bretherton, and D. Leon, 2011: Coupled vs. decoupled boundary layers in VOCALS-REx. Atmos. Chem. Phys., 11, 7143-7153, https://doi.org/10.5194/acp-11-7143-2011.

Jonker, H. J. J., and J. Vilà-Guerau de Arellano, 2005: The influence of chemistry on the length scales of reactive species in convective atmospheric boundary layers (in Russian). Khim. Fiz., 24, 87-96.

P. G. Duynkerke, and J. W. Cuijpers, 1999: Mesoscale fluctuations in scalars generated by boundary layer convection. J. Atmos. Sci., 56, 801-808, https://doi.org/10.1175/ 1520-0469(1999)056<0801:MFISGB > 2.0.CO;2.

Kirkpatrick, M. P., A. S. Ackerman, D. E. Stevens, and N. N. Mansour, 2006: On the application of the dynamic Smagorinsky model to large-eddy simulations of the cloud-topped atmospheric boundary layer. J. Atmos. Sci., 63, 526-546, https://doi.org/10.1175/JAS3651.1.

Lima, M. A., and J. W. Wilson, 2008: Convective storm initiation in a moist tropical environment. Mon. Wea. Rev., 136, 1847-1864, https://doi.org/10.1175/2007MWR2279.1.

Liou, K. N., and S. C. Ou, 1989: The role of cloud microphysical processes in climate: An assessment from a one-dimensional perspective. J. Geophys. Res., 94, 8599-8607, https://doi.org/ 10.1029/JD094iD06p08599.

Martin, G. M., D. W. Johnson, and A. Spice, 1994: The measurement and parameterization of effective radius of droplets in warm stratocumulus clouds. J. Atmos. Sci., 51, 1823-1842, https://doi.org/ 10.1175/1520-0469(1994)051<1823:TMAPOE $>2.0 . C O ; 2$.

Miller, M. A., and B. A. Albrecht, 1995: Surface-based observations of mesoscale cumulus-stratocumulus interaction during ASTEX. J. Atmos. Sci., 52, 2809-2826, https://doi.org/10.1175/ 1520-0469(1995)052<2809:SBOOMC >2.0.CO;2. 
Morrison, H., and W. W. Grabowski, 2008: Modeling supersaturation and subgrid-scale mixing with two-moment bulk warm microphysics. J. Atmos. Sci., 65, 792-812, https://doi.org/ 10.1175/2007JAS2374.1.

— J. A. Curry, and V. I. Khvorostyanov, 2005: A new doublemoment microphysics parameterization for application in cloud and climate models. Part I: Description. J. Atmos. Sci., 62, 1665-1677, https://doi.org/10.1175/JAS3446.1.

Muhlbauer, A., I. L. McCoy, and R. Wood, 2014: Climatology of stratocumulus cloud morphologies: Microphysical properties and radiative effects. Atmos. Chem. Phys., 14, 6695-6716, https://doi.org/10.5194/acp-14-6695-2014.

Müller, G., and A. Chlond, 1996: Three-dimensional numerical study of cell broadening during cold-air outbreaks. Bound-Layer Meteor., 81, 289-323, https://doi.org/10.1007/BF02430333.

Nakamura, K., M. Hara, A. T. Noda, H. Tomita, and Y. Wakazuki, 2012: Simulation and verification of tropical deep convective clouds using eddy-permitting regional atmospheric models II. Earth Simulator Center Annual Rep., 61-65, https://www. jamstec.go.jp/esc/publication/annual/annual2012/pdf/2project/ chapter1/061nakamura.pdf.

Pino, D., H. J. J. Jonker, J. Vilà-Guerau de Arellano, and A. Dosio, 2006: Role of shear and the inversion strength during sunset turbulence over land: Characteristic length scales. Bound.-Layer Meteor., 121, 537-556, https://doi.org/10.1007/ s10546-006-9080-6.

Pope, S. B., 2000: Turbulent Flows. Cambridge University Press, $771 \mathrm{pp}$.

Rosenfeld, D., Y. J. Kaufman, and I. Koren, 2006: Switching cloud cover and dynamical regimes from open to closed Benard cells in response to the suppression of precipitation by aerosols. Atmos. Chem. Phys., 6, 2503-2511, https://doi.org/10.5194/acp-6-2503-2006.

Savic-Jovcic, V., and B. Stevens, 2008: The structure and mesoscale organization of precipitating stratocumulus. J. Atmos. Sci., 65 , 1587-1605, https://doi.org/10.1175/2007JAS2456.1.

Schröter, M., S. Raasch, and H. Jansen, 2005: Cell broadening revisited: Results from high-resolution large-eddy simulations of cold air outbreaks. J. Atmos. Sci., 62, 2023-2032, https://doi.org/ 10.1175/JAS3451.1.

Seifert, A., 2008: On the parameterization of evaporation of raindrops as simulated by a one-dimensional rainshaft model. J. Atmos. Sci., 65, 3608-3619, https://doi.org/10.1175/ 2008JAS2586.1.

_- and T. Heus, 2013: Large-eddy simulation of organized precipitating trade wind cumulus clouds. Atmos. Chem. Phys., 13, 5631-5645, https://doi.org/10.5194/acp-13-5631-2013.

Shao, Q., and D. A. Randall, 1996: Closed mesoscale cellular convection driven by cloud-top radiative cooling. J. Atmos. Sci., 53, 2144-2165, https://doi.org/10.1175/1520-0469(1996)053<2144: $\mathrm{CMCCDB}>2.0 . \mathrm{CO} ; 2$.

Sharon, T. M., B. A. Albrecht, H. H. Jonsson, P. Minnis, M. M. Khaiyer, T. M. van Reken, J. Seinfeld, and R. Flagan, 2006. Aerosol and cloud microphysical characteristics of rifts and gradients in maritime stratocumulus clouds. J. Atmos. Sci., 63, 983-997, https://doi.org/10.1175/JAS3667.1.

Stevens, B., W. R. Cotton, G. Feingold, and C. H. Moeng, 1998: Large-eddy simulations of strongly precipitating, shallow, stratocumulus-topped boundary layers. J. Atmos. Sci., $\mathbf{5 5}$, 3616-3638, https://doi.org/10.1175/1520-0469(1998)055<3616: LESOSP $>2.0 . \mathrm{CO} ; 2$.

— stratocumulus-DYCOMS-II. Bull. Amer. Meteor. Soc., 84, 579-593, https://doi.org/10.1175/BAMS-84-5-579.

— tions via observations of nocturnal marine stratocumulus. Mon. Wea. Rev., 133, 1443-1462, https://doi.org/10.1175/ MWR2930.1.

Stull, R. B., 1988. An Introduction to Boundary Layer Meteorology. Kluwer Academic, $666 \mathrm{pp}$.

Terai, C. R., C. S. Bretherton, R. Wood, and G. Painter, 2014: Aircraft observations of aerosol, cloud, precipitation, and boundary layer properties in pockets of open cells over the southeast Pacific. Atmos. Chem. Phys., 14, 8071-8088, https:// doi.org/10.5194/acp-14-8071-2014.

Vali, G., R. D. Kelly, J. French, S. Haimov, D. Leon, R. E. McIntosh, and A. Pazmany, 1998: Finescale structure and microphysics of coastal stratus. J. Atmos. Sci., 55, 3540-3564, https://doi.org/ 10.1175/1520-0469(1998)055<3540:FSAMOC > 2.0.CO;2.

vanZanten, M. C., and B. Stevens, 2005: Observations of the structure of heavily precipitating marine stratocumulus. J. Atmos. Sci., 62, 4327-4342, https://doi.org/10.1175/JAS3611.1.

Wang, H., and G. Feingold, 2009: Modeling mesoscale cellular structures and drizzle in marine stratocumulus. Part I: Impact of drizzle on the formation and evolution of open cells. J. Atmos. Sci., 66, 3237-3256, https://doi.org/10.1175/2009JAS3022.1.

Wang, S., B. A. Albrecht, and P. Minnis, 1993: A regional simulation of marine boundary-layer clouds. J. Atmos. Sci., 50, 4022-4043, https://doi.org/10.1175/1520-0469(1993)050<4022: ARSOMB $>2.0 . \mathrm{CO} ; 2$.

Wood, R., 2005: Drizzle in stratiform boundary layer clouds. Part I: Vertical and horizontal structure. J. Atmos. Sci., 62, 3011-3033, https://doi.org/10.1175/JAS3529.1.

_ 2012: Stratocumulus clouds. Mon. Wea. Rev., 140, 2373-2423, https://doi.org/10.1175/MWR-D-11-00121.1.

— path in marine low cloud: The importance of mesoscale cellular convection. J. Climate, 19, 1748-1764, https://doi.org/ 10.1175/JCLI3702.1.

—, C. S. Bretherton, D. Leon, A. D. Clarke, P. Zuidema, G. Allen, and H. Coe, 2011: An aircraft case study of the spatial transition from closed to open mesoscale cellular convection over the southeast Pacific. Atmos. Chem. Phys., 11, 2341-2370, https://doi.org/10.5194/acp-11-2341-2011.

Xue, H., G. Feingold, and B. Stevens, 2008: Aerosol effects on clouds, precipitation, and the organization of shallow cumulus convection. J. Atmos. Sci., 65, 392-406, https://doi.org/10.1175/2007JAS2428.1.

Yamaguchi, T., and G. Feingold, 2015: On the relationship between open cellular convective cloud patterns and the spatial distribution of precipitation. Atmos. Chem. Phys., 15, 1237-1251, https://doi.org/10.5194/acp-15-1237-2015.

Zhou, X., T. Heus, and P. Kollias, 2017: Influences of drizzle on stratocumulus cloudiness and organization. J. Geophys. Res. Atmos., 122, 6989-7003, https://doi.org/10.1002/2017JD026641. 


\title{
Corrigendum
}

\author{
XiAOLI ZHOU \\ Department of Atmospheric and Oceanic Sciences, McGill University, Montreal, Quebec, Canada, \\ and Department of Atmospheric Sciences, University of Washington, Seattle, Washington \\ ANDrew S. ACKERMAN AND ANN M. FridLIND \\ NASA Goddard Institute for Space Studies, New York, New York \\ PAVlos Kollias \\ School of Marine and Atmospheric Sciences, Stony Brook University, State University of New York, Stony Brook, \\ and Department of Environmental and Climate Sciences, Brookhaven National Laboratory, Upton, New York
}

(Manuscript received 14 June 2018, in final form 14 September 2018)

There were errors in the units for the variance spectra in the legend of Fig. 4 and in the $y$-axis labels of Figs. 5a, 7, 14b, and 14c in Zhou et al. (2018). These errors did not affect any discussion or conclusions of the study. The corrected figures (Figs. 4, 5, 7, and 14) are shown below.

\section{REFERENCE}

Zhou, X., A. S. Ackerman, A. M. Fridlind, and P. Kollias, 2018: Simulation of mesoscale cellular convection in marine stratocumulus. Part I: Drizzling conditions. J. Atmos. Sci., 75, 257-274, https://doi.org/10.1175/ JAS-D-17-0070.1. 


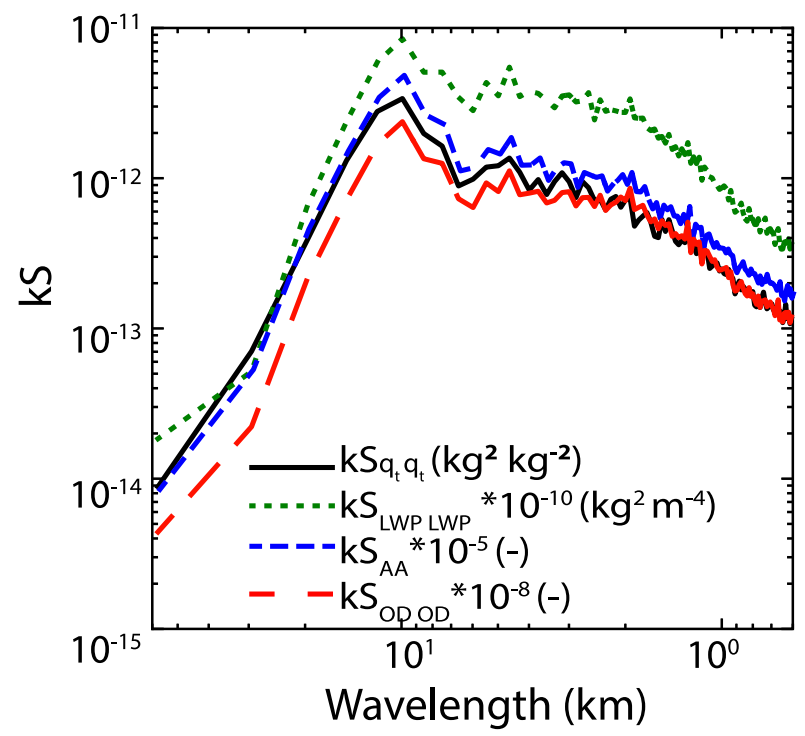

FIG. 4. Variance spectra of total water mixing ratio at $700 \mathrm{~m}$, LWP, pseudoalbedo, and optical depth for simulation Nd10 at $10 \mathrm{~h}$ multiplied by the wavenumber $k$.
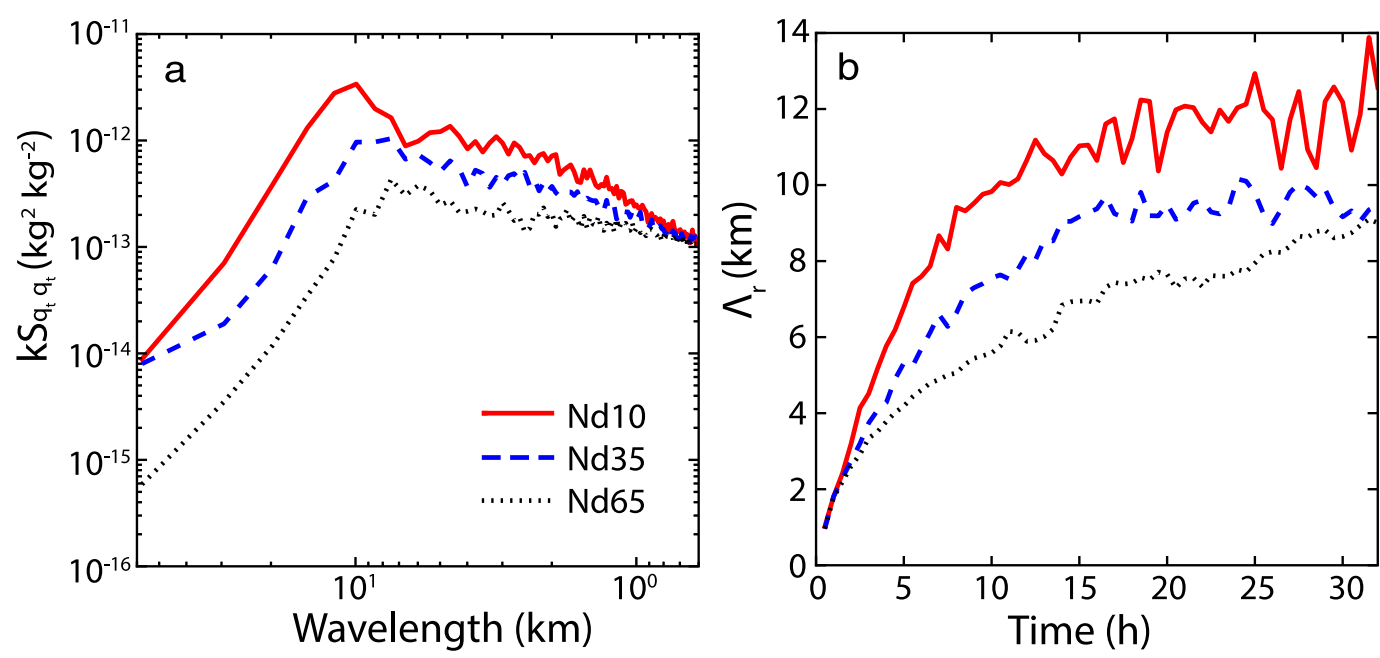

FIG. 5. (a) Variance spectra of total water mixing ratio at $700 \mathrm{~m}$ at $10 \mathrm{~h}$ multiplied by the wavenumber $k$ and (b) temporal evolution of total water mixing ratio variance length scale (defined in Zhou et al. 2018) at $700 \mathrm{~m}$ for Nd10, Nd35, and Nd65. Simulations as in Fig. 2 of Zhou et al. (2018). 

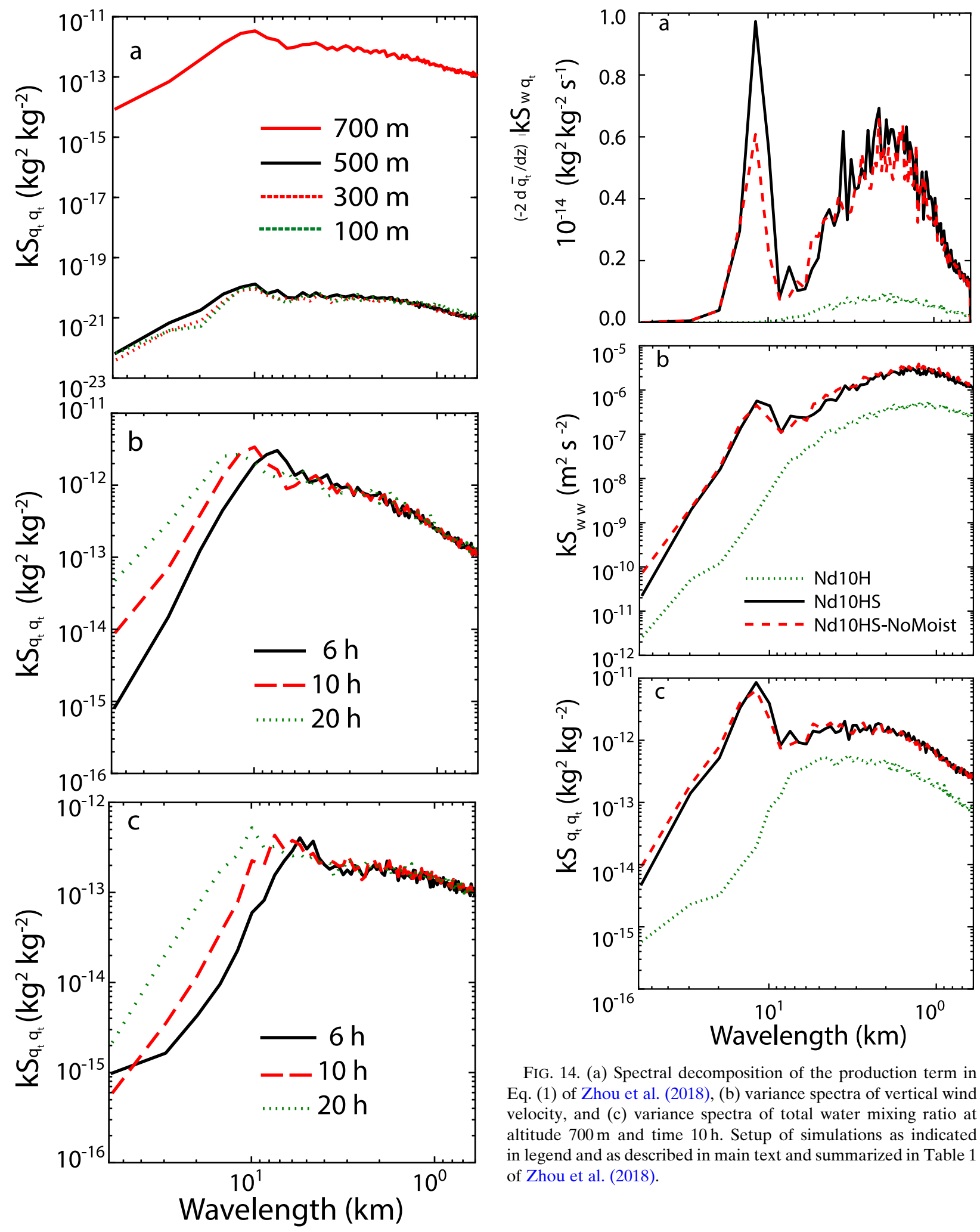

FIG. 14. (a) Spectral decomposition of the production term in Eq. (1) of Zhou et al. (2018), (b) variance spectra of vertical wind velocity, and (c) variance spectra of total water mixing ratio at altitude $700 \mathrm{~m}$ and time $10 \mathrm{~h}$. Setup of simulations as indicated in legend and as described in main text and summarized in Table 1 of Zhou et al. (2018).

FIG. 7. Variance spectra of total water mixing ratio of (a) Nd10 at different levels at $10 \mathrm{~h}$, (b) Nd10 at $700 \mathrm{~m}$ at three times, and (c) Nd65 at $700 \mathrm{~m}$ at three times. 